Canadian Studies in Population, Vol. 37.1-2, Spring/Summer, pp. 175-206

\title{
Cohort Working Life Tables for Older Canadians
}

\author{
Frank T. Denton \\ Christine H. Feaver \\ Byron G. Spencer \\ Department of Economics \\ McMaster University \\ Hamilton, Ontario, Canada \\ E-mail: spencer@mcmaster.ca
}

\begin{abstract}
We construct cohort working life tables for Canadian men and women aged 50 and older and, for comparison, corresponding period tables. The tables are derived using annual single-age time series of participation rates for 1976-2006 from the master files of the Statistics Canada Labour Force Survey. The cohort calculations are based on stochastic projections of mortality coupled with alternative assumptions about future participation rates. Separate tables are provided for the years 1976, 1991, and 2006, thus spanning a period of substantial gains in life expectancy and strong upward trends in female participation. Life expectancies based on the cohort tables are greater than those based on the period tables, for both men and women, and that is reflected in increased retirement expectancies. For example, a male aged 50 in 1976 could have expected to live three years longer and to have almost four more years in retirement, based on the male cohort table under medium assumptions, as compared with the corresponding period table.
\end{abstract}

Key Words: Cohort working life tables

CSP 2010, 37.1-2: 175-206 


\section{Résumé}

Nous avons établis des tables de vie active par génération pour les Canadiens et Canadiennes âgés de 50 ans ou plus ainsi que des tables du moment correspondantes pour servir de comparaison. Les tables sont dérivées à l'aide de séries chronologiques annuelles d'un seul âge pour le taux d'activité pour les années 1976 à 2006 provenant des fichiers maîtres de l'Enquête sur la population active de Statistique Canada. Les calculs par génération sont basées sur des projections stochastiques de mortalité et sur des suppositions quant à de futurs taux d'activité possibles. Des tables séparées ont été établies pour les années 1976, 1991 et 2006 ; ce qui représente une période qui a vu des gains substantiels en ce qui concerne l'espérance de vie et une forte hausse d'activité chez les femmes. Les espérance de vie basées sur les tables par génération sont plus élevées que celles basées sur les tables du moment, pour les hommes et les femmes ; ceci se traduit par des espérances de retraite accrues. Par exemple, un homme âgé de 50 en 1976 pouvait s'attendre à vivre trois ans de plus et à passer presque quatre ans de plus en retraite basé sur la table par génération avec des suppositions moyennes, comparé à la table du moment correspondante.

Mots-clés: Tables de vie active par génération

\section{Introduction}

Patterns of retirement - age-related permanent exit from the labour force, other than by death - are of interest from an actuarial perspective, and more generally as an important characteristic of economic and social life cycle behaviour. In the aggregate they bear on the availability of workers in the creation of national income, on the one hand, and on the share of that income going to support those who have retired, on the other. These considerations have special relevance for public policy at a time when the baby boom generation in North America and elsewhere is moving into the retirement zone while life expectancy continues on its long-run upward path. In that context, especially, working life tables provide a useful framework for exploring the demographic aspects of retirement. In this paper we develop working life tables for older Canadian cohorts and associated measures of work and retirement expectancy - average numbers of years in the labour force remaining, and then out of it, at different ages.

CSP 2010, 37.1-2: 175-206 
The basic life table, with its probabilities of death and survival, has a long history in demography as a device for drawing out the implications of a given age schedule of mortality rates, and its extension to include probabilities relating to the labour force - the working life table - goes back several decades (see Keyfitz 1968, Shryock and Siegel 1971, and Keyfitz and Carswell 2005, for descriptions of the formal framework). The working population is the population of prime interest for our purposes. In a closed population (no migration in or out) there is one way of entering that population and there are two ways of exiting it, death and the cessation of work while still alive. Cessation of work may be permanent (retirement, in the usual sense of that word) or temporary. Overall there is considerable movement back and forth between the working and nonworking populations (see Jones and Riddell, 1998, for example). However, our interest is in the population 50 years of age or older, and for that group the amount of temporary movement is much smaller. Just how one defines retirement is of course important. ${ }^{1}$ For present purposes we take declines in the rate of labour force participation at older ages as representing average retirement rates, implying that net changes from year to year are equal to gross changes, at older ages, so that retirement, like death, becomes an absorbing state, a state from which there is no return. That assumption would be quite unrealistic for younger ages but we think it a reasonable approximation for the population in the retirement or near-retirement age range, especially with the type of labour force data with which we are working (annual averages, which eliminate seasonal and much of other kinds of short term monthly movement). Indeed, it is a necessary approximation, given the data availability. ${ }^{2}$

Working life tables have been developed for various countries and various times. Most have been period tables - tables based on the mortality and labour force participation rates of a single period, usually a year or an average of a few years. Period tables published by Statistics Canada (or its predecessor, the Dominion Bureau of Statistics) include the tables for males in Denton and Ostry (1969) and in Gnanasekaran and Montigny (1975). Canadian period tables were constructed for females by Chow, Krishnan, and Lalu (1986) and for both sexes by Bélanger and Larrivée (1992), using, in the latter case, a multistate model in which movements into and out of the labour force are permitted at all ages. The tables in the earlier studies allowed only movements into the labour force prior to the age at which the peak participation rate occurred, and only movements out - "retirements" - beyond that age. For period tables produced for the U.S. by the Bureau of Labor Statistics, see Smith $(1982,1986)$ and references to earlier work therein, and in the studies just noted. There is also considerable interest in the use of working life tables for purposes of insurance contracts, litigation for injury-related compensation, the calculation of occupational hazard rates, and the like, and much of the more recent work on such tables has been carried out in that context. (see Markku 2005, Pflaum and McCollister 2007, Skoog and Ciecka 2006). Cohort tables - tables for people with a common date of birth - 
are more difficult to construct and rarer than period tables. For Canada, cohort calculations were made by Wolfson and Rowe (2001), using a multistate microsimulation framework, although it appears that the working life tables themselves were not actually published; for the U.S., a cohort table for males was constructed by Lee (2001). We make no pretense of being exhaustive but note also the following relevant cohort studies: Booth and Tickle (2004), Wilmoth (2005), Statistics New Zealand (2006), and Babel, Bomsdorf and Schmidt (2007).

The difficulty in constructing a table for a cohort of which some members are still living is that its life history is incomplete, requires forecasting, and is therefore subject to uncertainty. Our contribution in this paper is the construction of a new set of cohort tables, drawing on stochastic forecasting methods for life expectancy developed earlier (Denton, Feaver, and Spencer 2005) and making alternative assumptions about future labour force participation rates. We construct period tables also, for selected years, and compare them with the cohort tables.

We are fortunate in being able to take advantage of micro data files that have become available only recently for general research purposes, the master files of Statistics Canada's monthly Labour Force Survey (LFS), which are accessible now at the Statistics Canada Research Data Centre at McMaster University as well as at a number of other Canadian universities. All personal identification is removed from the files and strict security regulations are enforced so as to maintain the confidentiality of individual survey responses. The LFS files allow us to obtain estimates of annual average labour force participation rates for males and females by single years of age up to ages beyond which participation rates are so low as to be of little consequence. The estimates are subject to random sampling error and we therefore smooth the age profiles using a nonparametric smoother, as discussed below. The files go back to 1976 and we are thus able to construct a complete matrix of single-age annual participation rates for the 31-year period 1976-2006. From that we are able to derive the completed portions of cohort series for people aged 50 in 1976 (31 age observations), aged 50 in 1977 (30 observations), and so on, up to 2006 (a single observation, for age 50).

We have been referring to the series thus constructed as cohort series and will continue, for convenience, to refer to them in that way. However, strictly speaking they should be regarded as pseudo-cohort series. Unlike true cohort series they do not represent exactly the same individuals tracked from year to year over the course of their later adult lives. The LFS is not a longitudinal sample survey; it retains respondents for only six months and the composition of what we are referring to as a cohort thus changes over time. From that point of view the series should be regarded as sample estimates of the true cohort series. But the composition would change also, aside from mortality, as a result of immigration and emigration even if the LFS sample could somehow be replaced

CSP 2010, 37.1-2: 175-206 
by a complete census in every period. Most of the 60-year-olds in 1990, say, would be people who had been present as 50 -year-olds in the hypothetical census of 1980 but there would also be some who had come to Canada in the intervening decade, and some of the original number would have left the country. Nevertheless, the pseudo cohort series that we are able to construct can reasonably be assumed to provide a useful, albeit approximate, record of how cohorts' participation rates changed with age, and a suitable basis for the construction of working life tables.

We discuss the framework for working life tables in the next section and the data underlying the tables in the one following. We then describe the procedures we have used for making stochastic mortality projections and our alternative assumptions about future participation rates, as required for filling out the incomplete portions of cohort life paths. We present period tables for selected years, and then the cohort tables, discuss and compare the tables, note the changes in patterns that occur in going from older to younger cohorts, and explore the sensitivity of the calculations to differences in projections and assumptions. A final section provides some concluding comments.

\section{Framework}

The basic life table constructed from annual data incorporates a number of variables, all of which derive from a given set of death probabilities. The theoretical life table population is closed and stationary: there is no immigration or emigration and the population never changes in size or age distribution. For the population as a whole there is only one means of entry each year, by birth, and one means of exit, by death. We are concerned only with the population 50 and older, and for that, entrants are the previous year's 49-year-olds or the survivors of births half a century ago.

We define the life table variables of interest using more or less standard notation, where relevant, except that we find it convenient to write $1(\mathrm{x})$ rather than the more conventional $l_{x}$ and similarly for other variables.

Formal definitions are as follows:

\begin{tabular}{|c|c|c|}
\hline $\mathrm{x}$ & - & $\begin{array}{l}\text { exact age } x(x=0 \text { on the date of birth, } 1 \text { on the first } \\
\text { anniversary of that date, and so on) }\end{array}$ \\
\hline$x^{*}$ & - & $\begin{array}{l}\text { oldest age at which there are any survivors (we set } \\
\text { this to 109) }\end{array}$ \\
\hline $1(\mathrm{x})$ & - & population alive at age $\mathrm{x}$ \\
\hline$q(x)$ & - & $\begin{array}{l}\text { death rate, or probability that an individual of age } x \\
\text { will die before } x+1^{3}\end{array}$ \\
\hline$s(x)$ & - & $\begin{array}{l}\text { survival rate (equal to } 1-q(x) \text { ), or probability that an } \\
\text { individual of age } x \text { will not die before } x+1\end{array}$ \\
\hline
\end{tabular}

CSP 2010, 37.1-2: 175-206 


\begin{tabular}{|c|c|c|}
\hline $\mathrm{L}(\mathrm{x})$ & - & $\begin{array}{l}\text { total number of person-years lived during the interval } \\
x \text { to } x+1\end{array}$ \\
\hline $\mathrm{T}(\mathrm{x})$ & - & $\begin{array}{l}\text { total number of person-years yet to be lived, at age } \mathrm{x} \text {, } \\
\text { over the remaining life span (the sum of the } \mathrm{L}(\mathrm{x}) \\
\text { values from } \mathrm{x} \text { to } \mathrm{x}^{*} \text { ) }\end{array}$ \\
\hline $\mathrm{e}(\mathrm{x})$ & - & $\begin{array}{l}\text { life expectancy: mean years of life remaining to } \\
\text { individuals of age } x\end{array}$ \\
\hline
\end{tabular}

The initial population in a life table is set at some arbitrarily large number - 100,000, say, as in our tables at age 50 - and the surviving population is calculated at subsequent ages by applying survival probabilities: $1(x+1)=$ $\mathrm{s}(\mathrm{x}) 1(\mathrm{x})$, for $\mathrm{x}=51,52, \ldots, \mathrm{x}^{*}$. (Note that $\mathrm{s}\left(\mathrm{x}^{*}\right)=0$ ). It is assumed (as a close approximation for the age range of interest to us) that deaths occur uniformly throughout a year, allowing us to write $\mathrm{L}(\mathrm{x})=1 / 2(1(\mathrm{x})+1(\mathrm{x}+1)$. Average life expectancy at age $\mathrm{x}$ is then given by $\mathrm{e}(\mathrm{x})=\mathrm{T}(\mathrm{x}) / 1(\mathrm{x})$.

The foregoing definitions and relations apply to the standard life table framework. We extend the framework now to incorporate the working life table by adding a number of other variables, with symbols chosen to give them some mnemonic relevance:

\begin{tabular}{|c|c|c|}
\hline$f(x)$ & - & population in the labour force at age $\mathrm{x}$ \\
\hline $\mathrm{n}(\mathrm{x})$ & - & population not in the labour force at age $\mathrm{x}$ \\
\hline $\mathrm{p}(\mathrm{x})$ & - & $\begin{array}{l}\text { participation rate, or probability that an individual of } \\
\text { age } x \text { will be in the labour force }\end{array}$ \\
\hline $\mathrm{F}(\mathrm{x})$ & - & $\begin{array}{l}\text { total number of labour force person-years during the } \\
\text { interval } x \text { to } x+1\end{array}$ \\
\hline $\mathrm{TF}(\mathrm{x})$ & - & $\begin{array}{l}\text { total number of labour force person-years yet to be } \\
\text { lived, at age } x \text {, over the remaining life span (the sum } \\
\text { of the } F(x) \text { values from } x \text { to } x^{*} \text { ) }\end{array}$ \\
\hline $\mathrm{N}(\mathrm{x})$ & - & $\begin{array}{l}\text { total number of non-labour force person-years during } \\
\text { the interval } x \text { to } x+1\end{array}$ \\
\hline $\mathrm{TN}(\mathrm{x})$ & - & $\begin{array}{l}\text { total number of non-labour force person-years yet to } \\
\text { be lived, at age } x \text {, over the remaining life span (the } \\
\left.\text { sum of the } N(x) \text { values from } x \text { to } x^{*}\right)\end{array}$ \\
\hline ewl(x) & - & $\begin{array}{l}\text { working life expectancy of individuals in the } \\
\text { population: mean years in the labour force remaining } \\
\text { to individuals of age } \mathrm{x} \text {, whether or not they are in the } \\
\text { labour force at that age }\end{array}$ \\
\hline enl(x) & - & $\begin{array}{l}\text { nonworking life expectancy of individuals in the } \\
\text { population: mean years not in the labour force } \\
\text { remaining to individuals of age } \mathrm{x} \text {, whether or not they } \\
\text { are in the labour force at that age }\end{array}$ \\
\hline
\end{tabular}

CSP 2010, 37.1-2: 175-206 


\begin{abstract}
$\mathrm{r}(\mathrm{x}) \quad-\quad$ retirement rate, or probability that an individual member of the labour force of age $\mathrm{x}$ will have left the labour force by $\mathrm{x}+1$, other than because of death

ewf(x) - $\quad$ working life expectancy of individuals in the labour force: mean years in the labour force remaining to individuals who are in the labour force at age $\mathrm{x}$

$\operatorname{enf}(\mathrm{x}) \quad-\quad$ nonworking life expectancy of individuals in the labour force: mean years not in the labour force remaining to individuals who are in the labour force at age $x$
\end{abstract}

The ways in which these additional variables fit into the expanded framework are as follows. The total population is divided into two component populations at each age, labour force and non-labour force: $1(x)=f(x)+n(x)$, with average participation rate $\mathrm{p}(\mathrm{x})=\mathrm{f}(\mathrm{x}) / \mathrm{l}(\mathrm{x})$. Note that our definition of participation rate in the working life table context differs from that used in the Labour Force Survey. Our rate applies to the total population of a given age whereas the LFS rate applies to a more restricted population; see below for discussion. As with $\mathrm{T}(\mathrm{x})$, we assume again as a close approximation, that changes in the labour force occur evenly over the year, so that $F(x)=1 / 2(f(x)+$ $\mathrm{f}(\mathrm{x}+1)$.

The retirement rate, $r(x)$, is defined as the difference between the number in the labour force at age $\mathrm{x}+1$ and the number in the labour force at age $\mathrm{x}$ who survive to $x+1$, expressed as a ratio to the labour force at age $x$; that is, $r(x)=$ $[s(x) f(x)-f(x+1)] / f(x)=s(x)-f(x+1) / f(x)$.

There are two pairs of working/nonworking life expectancies; the distinctions are simple, but important. The first pair, ewl(x) and enl(x), relates to the combined population at each age, the labour force plus the non-labour force. Thus ewl $(\mathrm{x})=\mathrm{TF}(\mathrm{x}) / 1(\mathrm{x})$ and $\operatorname{enl}(\mathrm{x})=\mathrm{TN}(\mathrm{x}) / 1(\mathrm{x})$ are averages over the whole population, including people who are not in the labour force. Since the only two activity states are labour force and non-labour force the two expectancies partition overall life expectancy at each age into working and nonworking components: ewl $(\mathrm{x})+\mathrm{enl}(\mathrm{x})=\mathrm{e}(\mathrm{x})$. The working life expectancy in the second pair, on the other hand, relates specifically to people in the labour force: ewf(x) $=\mathrm{TF}(\mathrm{x}) / \mathrm{f}(\mathrm{x})$. Assuming the same life expectancy for people in the labour force and those not in the labour force, $\operatorname{enf}(\mathrm{x})$ is then equal to e (x) - ewf(x), and can be interpreted as the expected number of years of retirement for members of the labour force in a population cohort of age $\mathrm{x}$. The assumption that life expectancy is the same for the labour force and non-labour force must be regarded as an approximation but it is commonly made in the calculation of retirement expectancies at the aggregate level as opposed to occupation-specific expectancies, for example, where more specific mortality information may be available from actuarial or other sources.

CSP 2010, 37.1-2: 175-206 
The $\operatorname{ewf}(\mathrm{x})$ variable requires further comment. If movements relating to the labour force after age 50 were in one direction only, out, it could be regarded as exactly the average working life expectancy of people in the labour force at age $x$, and $\operatorname{enf}(\mathrm{x})$ as exactly the expected number of years in retirement of those people. However there may still be some movement into the labour force as well as out of it in the 50+ age range, and this implies some imprecision in interpretation. A small proportion of those present in the labour force at age $\mathrm{x}+1$ or older ages, and thus contributors to $\mathrm{TF}(\mathrm{x})$, might not have been in the labour force at age $\mathrm{x}$, and some of those who were in the labour force might subsequently have withdrawn temporarily. To associate $\mathrm{TF}(\mathrm{x})$ entirely with $\mathrm{f}(\mathrm{x})$ in the calculation of ewf(x), while convenient, is therefore not exactly correct. Nevertheless the calculations of $\operatorname{ewf}(\mathrm{x})$ and $\operatorname{enf}(\mathrm{x})$ provide good practical approximations to what are commonly thought of as remaining average years of work and retirement, and we shall treat them, and refer to them, in that way. (One would expect the error to diminish with age over the 50+ range - to be smaller at 60 than at 50, and smaller still at 70, with corresponding increases in the accuracy of ewf(x).

\section{Data}

Complete life tables are available from Statistics Canada for 1976 to 2001, at five-year intervals, and we have incorporated those into our own working life tables. Life tables for 2006 were created by using procedures built into the MEDS population projection software (Denton, Feaver, and Spencer, 1994, 2005a). We estimated life tables for years within the five year intervals using linearly interpolated values of $\mathrm{q}(\mathrm{x})$. For years beyond 2006 (required for completing incomplete cohort histories) we used the stochastic forecasting methods described below.

The labour force participation rates needed for the working life tables were derived from the Labour Force Survey master files housed in the Statistics Canada Research Data Centre at McMaster University. Participation rates are published by Statistics Canada only for five-year age groups, with an openended $70+$ group. However, using the master files it was possible to calculate annual rates for males and females by single years of age for every year from 1976 to 2006, and to do so for ages beyond 70. Confidentiality restrictions came into play at very old ages but at those ages the participation rates were close enough to zero to be of negligible importance.

We adjusted the original participation rates in three ways. The first adjustment had to do with the population to which the rates pertain. The LFS excludes four categories from the population that it covers, at the national level: residents of the Yukon, Northwest Territories, and Nunavut; persons living on reserves or other Aboriginal settlements; full-time members of the Canadian 
armed forces; and inmates of institutions. We have adjusted the original rates to make them apply to the whole population by multiplying the rate at each age by the ratio of the LFS target population to the total annual mid-year population at that age, leaving out the three territories. That means that our adjusted rates are intended to apply to a population that excludes the territories but includes reserves, the armed forces, and institutions. To the extent that people in the excluded categories have participation rates different from those of the same age in the rest of the population, using common rates for both will be in error. But the numbers indicate that the errors must be small; it would take extremely large differences to produce errors of significant magnitude at the aggregate level to which our tables apply. We are thus satisfied with the use of an undifferentiated set of rates, and indeed have no realistic alternative, given the lack of sufficient information to permit us to do otherwise.

The second adjustment involves what we may call age centering. The LFS rates for males aged 50 relate to people who have had their 50th birthday but not yet their 51st. In accordance with the life table definitions, though, age $\mathrm{x}$ is taken to mean exact age $\mathrm{x} ; 50$ is taken to be exactly 50. Assuming that birthdays are distributed evenly over the year, 50 in the LFS actually means 50.5 , on average. We therefore shift the rates half a year by averaging the rates for consecutive pairs of ages - by averaging the rates for ages 49 and 50 to get the exact-age rate for 50-year-olds, the rates for ages 50 and 51 to get the exactage rate for 51-year-olds, and so on.

The third adjustment involves smoothing. After modifying the LFS participation rates to take account of population coverage and centering them, we plotted each of the single-age series separately for males and females over the 1976-2006 period. The LFS is a sample survey and the effects of random sampling error were apparent in the year-to-year fluctuations in the plotted series (as one would expect of estimates for relatively small groups, such as male or female single-age groups). We therefore smoothed each of the series using a nonparametric smoothing procedure implemented in the SHAZAM econometric software (Whistler et al. 2004), while being careful (as best we could) not to smooth out "meaningful" variations. We used, for that purpose, a Gaussian kernel smoothing method (see Härdle, 1990). Kernel methods require the choice of a bandwidth parameter value. We made a separate choice for each single-age series, based in most cases on the commonly used criterion of minimum cross-validation mean square error, coupled with visual inspection of plots of the smoothed and unsmoothed series to make sure that the smoothing results appeared sensible to the eye.

It is perhaps worth noting that we interpret the labour force as the working population, thus including both the employed and unemployed. This is consistent with the interpretation in earlier work on working life tables. We use "working" and "being in the labour force" to mean the same thing for our purposes.

CSP 2010, 37.1-2: 175-206 


\section{Stochastic Mortality Projections}

Future $\mathrm{q}(\mathrm{x})$ values as far out as 2064 are needed to fill out completely the mortality experiences of incomplete cohorts (cohorts of age 50 or more in 2006), implying a projection period of 58 years, with 2006 as starting point. To state the obvious, there is uncertainty about future mortality, and with that in mind we employ a method developed by us in earlier work for generating projections of the probability distribution of future $\mathrm{q}(\mathrm{x})$ values, rather than single projections stochastic projections, to use the term that is common in the literature. The earlier work is reported in Denton, Feaver, and Spencer (2005). A detailed description is available in that publication; we provide here an abbreviated version.

The stochastic projection of mortality rates was pioneered by Ronald Lee of the University of California at Berkeley and his associates. The Lee-Carter method, as it is called, has been used in various projections for the U.S. and other countries. (See Lee and Carter 1992, Lee and Tuljapurkar 1994, and other studies cited in Denton, Feaver and Spencer 2005) Our method is similar "in spirit" to the Lee-Carter method - it infers probability distributions from historical time series - and appears to deliver similar projection results, but it is different in procedure. It draws its inspiration from the broad class of resampling methods now in widespread use in the theoretical and applied statistical literature. It is an overlapping block bootstrap method, in the sense in which those words are used in the literature (Hall 1985, Künsch 1989).

The method that we use is one of three described in our article noted above. All three methods involve bootstrap procedures and all three have been found to deliver similar projection results. For present purposes our choice is a fully nonparametric technique, meaning that it requires no formal model and no assumption of a specific type of probability distribution, such as a normal distribution, for example. As a bootstrapping procedure it involves re-sampling the historical series of mortality rates (more correctly, the differences in the logarithms of those rates) and the generation of a very large number of possible, randomly determined future time paths of mortality rates and life expectancies.

A summary description of the method is as follows. We start with time series of annual mortality rates for the period 1926-2001 calculated from Statistics Canada historical numbers of deaths and census or estimated intercensal population figures. Separate series are derived for males and females in each of 19 age groups, yielding 38 in total. The first differences of the logarithms are then calculated for each of these 38 series, yielding 75 annual log differences. The bootstrapping procedure commences by selecting randomly from the 75-year log-difference series with equiprobable starting points a block or sequence of 25 years, converting the log differences in the block to age-sex-

CSP 2010, 37.1-2: 175-206 
specific $\mathrm{q}(\mathrm{x})$ values, and using those values to move the 2006 life table population $(1(\mathrm{x}))$ forward, one year at a time, for the first 25 years of the projection period. A new block of log differences is then selected, or possibly by chance, the same block, since the random sampling is with replacement and the population is moved forward another 25 years. Finally, a third block is selected, and the population is moved forward again, for the remaining number of years required to fill out the balance of the 58-year projection period. Only the first eight years of the 25 are required at this point; the remaining 17 are ignored. With the $\mathrm{q}(\mathrm{x})$ and $\mathrm{l}(\mathrm{x})$ values then given, the period life expectancy $(\mathrm{e}(\mathrm{x}))$ can be calculated at each age; the first set of "observations" on future life expectancies is now in place. The process then starts all over. New 25 -year blocks of log differences are selected and used to move the population forward to the end of the projection period, as before, and a second set of life expectancies is calculated. In total the process is repeated 10,000 times, giving 10,000 possible future sets of $\mathrm{e}(\mathrm{x})$ values for every year. For any given year in the projection period one can derive summary measures of the distributions, including an estimate of the probability that life expectancy at any given age will lie in some specified range. We choose three sets of summary measures for presentation purposes: median life expectancy which is the value that cuts off 50 percent of the 10,000-item distribution on each side, the 5th percentile which is the value that cuts off the lower 5 percent, and the 95 th percentile that cuts off the upper 5 percent. The differences between the 5th and 95th percentiles can be viewed as similar to 90 percent confidence intervals in standard statistical inference.

Two other aspects of the procedure should be noted. First, when a 25 -year block is selected randomly the annual log differences for the 38 age-sex groups within the block are all included, and used jointly in the projection calculations. This preserves the structure of correlations among the group mortality rates, which would not be the case if each group were treated independently. One would expect that mortality rates for consecutive age groups would be highly correlated, or rates for males and females in the same age group, for example. Thus one can think of the sampling unit as being a $38 \times 25$ matrix of the log differences -38 groups, 25 years. Secondly, a feature of the block bootstrapping method (especially of note with comparatively long blocks, as here) is that it preserves serial correlation in the time series of mortality rates within a block, particularly the correlation between consecutive annual rates. There may be discontinuities at the point where one sample block meets another but that is an unavoidable feature of the block bootstrap method.

CSP 2010, 37.1-2: 175-206 


\section{Alternative Future Participation Rates}

The choices of alternative assumptions about future changes in participation rates are made somewhat arbitrarily but based on our judgement as to reasonable ranges, in light of past history. We obviously do not know what the changes will be and we know of no theory that would provide reliable guidance. The rates for older males declined consistently for a long time and one spoke with confidence about the long-run trend towards earlier retirement. But the rates stopped declining rather suddenly and started to rise in the mid-to-late 1990s. As far as we know, no one predicted the turnaround, at least not publicly with any prominence, and we would be sceptical today of any confident assertions about what will happen in the next few years or decades. Our approach in this study is simply to examine from plots the time series patterns of age-specific rates, make what seem to be reasonable assumptions about future ranges, and use those to establish alternative bounds for the future experience of incomplete cohorts. The aim is to explore the sensitivity of the cohort working life tables to alternative assumptions about participation rates, as well as to the alternative projections of mortality rates discussed in the previous section.

We make medium, high, and low assumptions. The medium assumption is the same for males and females at every age - continuation of participation rates at their 2006 levels. The high and low assumptions are as follows (the rates are in percentage form):

Males in the range 50-65: high assumption - the rate at each age increases, by 2026, to the highest level observed (after smoothing) in the 1976-2006 data period; low assumption - the rate at each age decreases by same amount that it increases under the high assumption.

Males in the range 66-70: high assumption - the rate at each age increases so as to be 5 percentage points above the 2006 rate by 2026; low assumption - the rate at each age decreases so as to be 5 percentage points below the 2006 rate by 2026 .

Females in the range 50-70: high assumption - the rate at each age increases so as to be the same as the 2006 male rate by 2026; low assumption - no change (same as the medium assumption).

Males and females aged 71: high assumption - the rate for each sex increases so as to be 4 percentage points above the 2006 rate by 2026; low assumption - the rate for each sex decreases so as to be 4 percentage points below the 2006 rate by 2026 . 
Males and females aged 72: high assumption - the rate for each sex increases so as to be 3 percentage points above the 2006 rate by 2026 ; low assumption - the rate for each sex decreases so as to be 3 percentage points below the 2006 rate by 2026 .

Males and females aged 73: high assumption - the rate for each sex increases so as to be 2 percentage points above the 2006 rate by 2026; low assumption - the rate for each sex decreases so as to be 2 percentage points below the 2006 rate by 2026 .

Males and females aged 74: high assumption - the rate for each sex increases so as to be 1 percentage point above the 2006 rate by 2026; low assumption - the rate for each sex decreases so as to be 1 percentage point below the 2006 rate by 2026 .

Males and females 75 and over: no high/low differentiation; the rate for each sex at each age remains constant at the 2006 level.

Where changes occur, rates are assumed to move linearly between 2006 and 2026, and then to remain constant thereafter. Note that the high and low assumptions for 71 and above are set so as to maintain reasonable continuity from one age to the next: 4 percent increase at age 71,3 percent at 72 , and so on, to 0 percent increases at ages 75 and older.

\section{Period Tables}

We have constructed period tables for selected years, for comparison with the cohort tables, and we discuss these first. Table 1 presents period results for males and females of ages 50 to 75 , at five-year age intervals, for the years 1976, 1991, and 2006.

The initial age-50 population in Table 1, as in other tables, is set at 100,000. The table displays the surviving population at subsequent ages, $1(\mathrm{x})$, the associated death probabilities, $\mathrm{q}(\mathrm{x})$, and the average life expectancies, $\mathrm{e}(\mathrm{x})$. From the working life extension of the basic life table it displays the numbers in and not in the labour force, $\mathrm{f}(\mathrm{x})$ and $\mathrm{n}(\mathrm{x})$, and the participation rate (probability of being in the labour force), $\mathrm{p}(\mathrm{x})$. The two sets of working/nonworking life expectancies are shown: ewl(x) and enl(x) for the age $\mathrm{x}$ population as a whole and $\operatorname{ewf}(\mathrm{x})$ and $\operatorname{enf}(\mathrm{x})$ for the working (labour force) population. Also shown are the ratios of nonworking life expectancy to total life expectancy, enl/e(x) and enf/e(x). In the case of enf/e(x) the ratio can be interpreted as the fraction of the remaining years of life that will be spent in retirement by those who are still working at age $\mathrm{x}$.

CSP 2010, 37.1-2: 175-206 
Table 1

Period Working Life Tables, Selected Ages: Males and Females, Canada: 1976, 1991 and 2006

\begin{tabular}{|c|c|c|c|c|c|c|c|c|c|c|c|c|}
\hline \multirow{2}{*}{$\begin{array}{l}\text { Year and } \\
\text { Variable }\end{array}$} & \multicolumn{6}{|c|}{ Males } & \multicolumn{6}{|c|}{ Females } \\
\hline & $\mathbf{x}=\mathbf{5 0}$ & $x=55$ & $x=60$ & $x=65$ & $x=70$ & $x=75$ & $\mathbf{x}=\mathbf{5 0}$ & $x=55$ & $x=60$ & $x=65$ & $x=70$ & $x=75$ \\
\hline \multicolumn{13}{|l|}{$\underline{1976}$} \\
\hline I(x) & 100,000 & 95,604 & 88,980 & 79,613 & 67,206 & 51,895 & 100,000 & 97,803 & 94,511 & 89,661 & 82,493 & 72,054 \\
\hline$q(x)$ & 0.0073 & 0.0118 & 0.0184 & 0.0280 & 0.0425 & 0.0636 & 0.0038 & 0.0057 & 0.0087 & 0.0136 & 0.0217 & 0.0354 \\
\hline$e(x)$ & 24.9 & 20.9 & 17.2 & 14.0 & 11.0 & 8.6 & 30.5 & 26.1 & 22.0 & 18.0 & 14.3 & 11.0 \\
\hline$f(x)$ & 94,625 & 82,023 & 68,250 & 35,276 & 10,902 & 4,423 & 50,314 & 40,063 & 30,308 & 13,120 & 4,015 & 1,293 \\
\hline$n(x)$ & 5,375 & 13,580 & 20,730 & 44,336 & 56,304 & 47,472 & 49,686 & 57,740 & 64,203 & 76,541 & 78,478 & 70,761 \\
\hline $\mathbf{p}(\mathbf{x})$ & 0.946 & 0.858 & 0.767 & 0.443 & 0.162 & 0.085 & 0.503 & 0.410 & 0.321 & 0.146 & 0.049 & 0.018 \\
\hline $\operatorname{ewl}(x)$ & 12.3 & 8.3 & 4.6 & 1.8 & 0.8 & 0.4 & 5.6 & 3.5 & 1.7 & 0.6 & 0.2 & 0.1 \\
\hline enl(x) & 12.5 & 12.6 & 12.6 & 12.2 & 10.2 & 8.2 & 24.9 & 22.7 & 20.3 & 17.4 & 14.1 & 10.9 \\
\hline enl $/ \mathbf{e}(\mathbf{x})$ & 0.504 & 0.604 & 0.732 & 0.871 & 0.927 & 0.957 & 0.816 & 0.867 & 0.922 & 0.968 & 0.984 & 0.992 \\
\hline $\mathbf{r}(\mathbf{x})$ & 0.033 & 0.021 & 0.117 & 0.378 & 0.150 & 0.173 & 0.050 & 0.041 & 0.116 & 0.303 & 0.188 & 0.161 \\
\hline $\operatorname{ewf}(x)$ & 13.0 & 9.6 & 6.0 & 4.1 & 5.0 & 4.3 & 11.1 & 8.5 & 5.3 & 4.0 & 4.7 & 5.1 \\
\hline $\operatorname{enf}(x)$ & 11.8 & 11.2 & 11.2 & 9.9 & 6.1 & 4.2 & 19.4 & 17.7 & 16.6 & 14.0 & 9.6 & 5.9 \\
\hline enf $/ \mathbf{e}(x)$ & 0.476 & 0.538 & 0.650 & 0.709 & 0.549 & 0.496 & 0.635 & 0.676 & 0.758 & 0.779 & 0.669 & 0.536 \\
\hline \multicolumn{13}{|l|}{1991} \\
\hline $1(x)$ & 100,000 & 97,245 & 92,759 & 85,728 & 75,673 & 62,095 & 100,000 & 98,358 & 95,811 & 91,948 & 86,187 & 77,645 \\
\hline$q(x)$ & 0.0045 & 0.0075 & 0.0128 & 0.0204 & 0.0320 & 0.0506 & 0.0027 & 0.0043 & 0.0068 & 0.0106 & 0.0167 & 0.0278 \\
\hline$e(x)$ & 27.6 & 23.4 & 19.4 & 15.7 & 12.5 & 9.6 & 32.8 & 28.3 & 24.0 & 19.9 & 16.0 & 12.5 \\
\hline$f(x)$ & 91,133 & 78,866 & 58,610 & 25,619 & 8,811 & 4,135 & 71,923 & 53,111 & 33,754 & 11,818 & 3,370 & 1,548 \\
\hline $\mathrm{n}(\mathrm{x})$ & 8,867 & 18,378 & 34,149 & 60,109 & 66,862 & 57,960 & 28,077 & 45,247 & 62,056 & 80,130 & 82,817 & 76,096 \\
\hline $\mathbf{p}(\mathbf{x})$ & 0.911 & 0.811 & 0.632 & 0.299 & 0.116 & 0.067 & 0.719 & 0.540 & 0.352 & 0.129 & 0.039 & 0.020 \\
\hline $\operatorname{ewl}(x)$ & 11.2 & 7.1 & 3.6 & 1.4 & 0.7 & 0.3 & 6.9 & 3.9 & 1.7 & 0.5 & 0.2 & 0.1 \\
\hline enl(x) & 16.5 & 16.3 & 15.7 & 14.3 & 11.8 & 9.3 & 25.9 & 24.4 & 22.3 & 19.4 & 15.8 & 12.4 \\
\hline enl/e(x) & 0.595 & 0.697 & 0.813 & 0.909 & 0.944 & 0.964 & 0.789 & 0.863 & 0.931 & 0.973 & 0.988 & 0.994 \\
\hline $\mathbf{r}(\mathbf{x})$ & 0.018 & 0.038 & 0.133 & 0.296 & 0.129 & 0.124 & 0.040 & 0.044 & 0.146 & 0.265 & 0.158 & 0.190 \\
\hline $\operatorname{ewf}(x)$ & 12.3 & 8.7 & 5.7 & 4.8 & 6.0 & 5.2 & 9.6 & 7.2 & 4.7 & 4.1 & 5.1 & 3.7 \\
\hline $\operatorname{enf}(x)$ & 15.4 & 14.6 & 13.6 & 10.9 & 6.5 & 4.5 & 23.2 & 21.1 & 19.3 & 15.8 & 11.0 & 8.9 \\
\hline enf $/ \mathbf{e}(x)$ & 0.556 & 0.626 & 0.704 & 0.695 & 0.522 & 0.464 & 0.706 & 0.747 & 0.804 & 0.793 & 0.683 & 0.708 \\
\hline \multicolumn{13}{|l|}{$\underline{2006}$} \\
\hline $\mathbf{l}(x)$ & 100,000 & 98,265 & 95,378 & 90,662 & 83,346 & 72,477 & 100,000 & 98,772 & 96,777 & 93,702 & 88,945 & 81,734 \\
\hline$q(x)$ & 0.0029 & 0.0047 & 0.0081 & 0.0135 & 0.0222 & 0.0373 & 0.0020 & 0.0033 & 0.0053 & 0.0085 & 0.0136 & 0.0225 \\
\hline$e(x)$ & 30.5 & 26.0 & 21.7 & 17.7 & 14.1 & 10.8 & 34.4 & 29.8 & 25.4 & 21.1 & 17.1 & 13.4 \\
\hline$f(x)$ & 91,007 & 81,153 & 62,847 & 33,354 & 11,753 & 5,390 & 80,290 & 69,636 & 46,289 & 19,550 & 5,756 & 1,822 \\
\hline$n(x)$ & 8,993 & 17,112 & 32,532 & 57,309 & 71,593 & 67,087 & 19,710 & 29,136 & 50,489 & 74,152 & 83,190 & 79,912 \\
\hline $\mathbf{p}(\mathbf{x})$ & 0.910 & 0.826 & 0.659 & 0.368 & 0.141 & 0.074 & 0.803 & 0.705 & 0.478 & 0.209 & 0.065 & 0.022 \\
\hline $\operatorname{ewl}(x)$ & 12.0 & 7.8 & 4.3 & 1.8 & 0.8 & 0.4 & 9.2 & 5.5 & 2.6 & 0.9 & 0.3 & 0.1 \\
\hline enl(x) & 18.6 & 18.2 & 17.5 & 15.9 & 13.2 & 10.4 & 25.2 & 24.3 & 22.8 & 20.3 & 16.8 & 13.3 \\
\hline enl/e(x) & 0.608 & 0.700 & 0.804 & 0.897 & 0.943 & 0.963 & 0.733 & 0.816 & 0.899 & 0.959 & 0.982 & 0.991 \\
\hline $\mathbf{r}(\mathbf{x})$ & 0.014 & 0.036 & 0.073 & 0.232 & 0.180 & 0.034 & 0.015 & 0.051 & 0.113 & 0.280 & 0.201 & 0.159 \\
\hline ewf(x) & 13.2 & 9.4 & 6.5 & 5.0 & 5.7 & 5.4 & 11.4 & 7.8 & 5.4 & 4.2 & 4.7 & 5.5 \\
\hline $\operatorname{enf}(x)$ & 17.4 & 16.6 & 15.3 & 12.8 & 8.3 & 5.4 & 23.0 & 22.1 & 20.0 & 16.9 & 12.4 & 7.9 \\
\hline enf $/ \mathbf{e}(\mathbf{x})$ & 0.569 & 0.637 & 0.703 & 0.720 & 0.594 & 0.499 & 0.668 & 0.740 & 0.789 & 0.801 & 0.727 & 0.586 \\
\hline
\end{tabular}

CSP 2010, 37.1-2: 175-206 
A period working life table is based entirely on the death probabilities and participation rates of a given period, in our case a year. It can be interpreted as depicting a stationary population in which those rates never change and in which the size and age distribution of the population and labour force never change either. Comparing the table for one year with that of another then amounts to comparing two different stationary populations. With that in mind we can note a few of the more interesting features of the tables for males and females in Table 1. First the changing life expectancy for males: 24.9 years at age 50 in 1976, 27.6 in 1991, 30.5 in 2006, with corresponding increases at older ages. Associated with these changes, about 52 percent of the age- 50 population would still be living at age 75, based on the 1976 survival rates, 62 percent based on the 1991 rates, and 72 percent based on the 2006 rates. The rate of survival from age 50 to age 75 thus increased by almost two-fifths over the three decades.

Life expectancy has been higher for females than for males, historically, for a very long time, and the continuation of the difference can be seen in Table 1: average years of life remaining at age 50 increased for women from 30.5 in 1976 to 34.4 in 2006, and the 25 year survival rate from about 72 percent to 82 percent, an increase of some 13 percent - notably smaller than the increase in the male rate, reflecting some narrowing of the male/female life expectancy gap, but the gap persists. Overall, the basic demographic background to the analysis of changing work/retirement patterns is thus declining mortality rates, increased life expectancies, and higher survival proportions among the older population.

The historic shift in the labour force participation rates of women is reflected also in Table 1. About 50 percent of all women were in the labour force at age 50 in $1976(\mathrm{p}(\mathrm{x})=0.503$ at $\mathrm{x}=50)$; by 2006 the proportion had risen to 80 percent. The expected number of years of work remaining for those in the labour force $(\operatorname{ewf}(\mathrm{x}))$ was somewhat lower than for men in all three years shown in the table, the expected number of years of retirement higher, and the ratio of retirement years to years of life remaining correspondingly higher too, by virtue of lower participation rates combined with greater life expectancy.

The participation rates shown at five-year intervals in Table 1 decline monotonically from age 50 through to age 75 , with the path of decline steeper for women than for men. Comparing the 2006 patterns, the male participation rate was 0.910 at age 50, 0.659 at 60 , and 0.368 at 65 ; the corresponding female rates were $0.803,0.478$, and 0.209 . In sum, women had lower participation rates and tended to retire earlier, based on the period tables.

CSP 2010, 37.1-2: 175-206 


\section{Cohort Tables}

We have constructed cohort tables in a fashion similar to the period ones. The three that we focus on are for males and females who were 50 years of age in 1976, 1991, and 2006, and the results for those are presented in Table 2. The format for Table 2 is identical to that of Table 1. As there, the variables of interest are reported at ages 50 to 75 , at five-year age intervals. Further results for male and female cohorts that were 50 in 1976, hence 80 in 2006, and thus the longest ones for which actual histories are available - indeed available for virtually all of their working lives - are shown in the form of plots in Figure 1.

The age paths of the 50-in-1976 cohorts in the figure give a good summary picture of the average late-adult-life patterns. Life expectancies, e (x), decline smoothly with age, the female path being everywhere above that of the male path. The labour force participation rates, $\mathrm{p}(\mathrm{x})$, decline continuously in both cases, aside from one or two minor aberrations caused almost certainly by sampling fluctuations in the underlying data. The expected length of working life for males in the labour force, ewf(x), declines to the mid-60s, rises somewhat (for those who are still active), remains roughly constant for a few years, and then starts to decline again. The corresponding expectancies for females are quite similar over most of the age range. (The participation rates are so small at the very oldest ages, and subject to such proportionately large sampling variability, that differences in the calculated expectancies there are much less reliable.) The corresponding retirement expectancies, enf(x), show only small changes until the early to mid-60s and then fall off sharply, with the expectancies markedly greater for females at most ages. The ratio of expected retirement years to expected life years, enf/e(x), rises for those in the labour force until the mid-60s and then declines, with the female ratios again consistently higher than the male ratios at most ages.

The differential effects of life expectancies on male and female retirement expectancies stand out clearly. A 50-in-1976 male who was still in the labour force at age 60 in 1986, for example, could have looked forward, on average, to 5.4 more years of work and 14.8 years of retirement, based on the cohort calculations. A female in the labour force at the same age could have looked forward to 5.1 years of work and 19.9 years of retirement.

The remaining series shown in Figure 1 are the year-to-year retirement rates, $\mathrm{r}(\mathrm{x})$, and they require some special comment. The definition of $\mathrm{r}(\mathrm{x})$ is the number of people who are in the labour force at age $\mathrm{x}$, survive to $\mathrm{x}+1$, and are not in the labour force at $\mathrm{x}+1$, evaluated as a proportion of the labour force at $\mathrm{x}$. This is equivalent to $\mathrm{r}(\mathrm{x})=\mathrm{s}(\mathrm{x})-\mathrm{f}(\mathrm{x}+1) / \mathrm{f}(\mathrm{x})$, as noted earlier. Making substitutions based on $\mathrm{f}(\mathrm{x})=\mathrm{p}(\mathrm{x}) 1(\mathrm{x})$ and $1(\mathrm{x}+1)=\mathrm{s}(\mathrm{x}) 1(\mathrm{x})$, and rearranging terms, we can also write $r(x)=-s(x)[p(x+1)-p(x)] / p(x)$ or, to a close approximation, $\mathrm{r}(\mathrm{x})=-\mathrm{s}(\mathrm{x}) \ln \mathrm{p}^{\prime}(\mathrm{x})$, where $\ln \mathrm{p}^{\prime}(\mathrm{x})$ is the first derivative of the

CSP 2010, 37.1-2: 175-206 
Figure 1

Selected Life and Working Life Characteristics of Male and Female Cohorts of Age 50 for Canada: 1976 (medium projection assumptions)
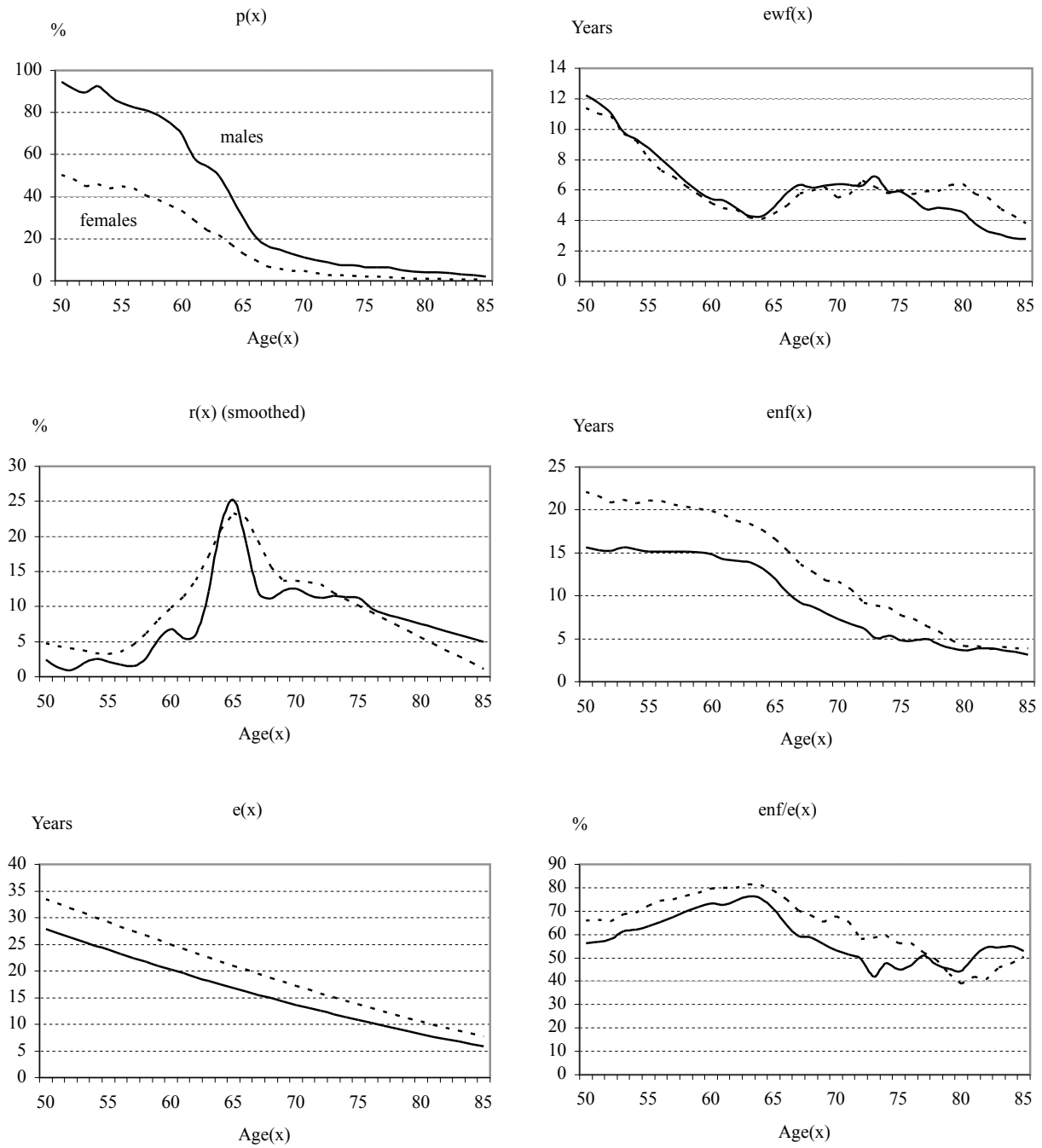
$\log$ of $\mathrm{p}(\mathrm{x})$ with respect to $\mathrm{x}$. The change in $\mathrm{r}(\mathrm{x})$, represented by its first derivative, is then $\mathrm{r}^{\prime}(\mathrm{x})=-\left[\mathrm{s}(\mathrm{x}) \operatorname{lnp} \mathrm{n}^{\prime \prime}(\mathrm{x})+\operatorname{lnp}^{\prime}(\mathrm{x}) \mathrm{s}^{\prime}(\mathrm{x})\right]$, where " represents a second derivative. Thus the change is a function of the first and second derivatives of the log participation rate and the first derivative of the survival rate. The point of all this is that changes in $\mathrm{r}(\mathrm{x})$ are extremely sensitive to changes in those rates, and the more so to changes in the changes of the participation rate.

The calculated single-age $\mathrm{r}(\mathrm{x})$ series reflect this sensitivity; they are subject to erratic fluctuations from one age to the next. However there are discernible underlying patterns. To bring out those patterns we have smoothed the $\mathrm{r}(\mathrm{x})$ series and it is the smoothed series that are shown in Figure 1 (though not in table 2). A nonparametric function was again used, supplemented by judgmental smoothing at the oldest ages, where the numbers are very small. The smoothed series indicate that the rate of retirement for each of the 50-in-1976 cohorts rises to a peak at about 65 and then falls off. There are minor differences between males and females but the patterns are essentially similar.

Comparisons of the cohort and period working life tables are of particular interest. Imagine an average 50-year-old in 1976, say, who is considering his/her work, life, and retirement future. The period tables assume fixed death and participation rates whereas the cohort tables allow for changes. How much difference would it make to the perceived future of our hypothetical 50-year-old whether he/she used the period table for 1976 or a table that related specifically to his/her cohort?

The comparisons can be made by matching the results in Table 2 with those in Table 1 and by looking at Figures 2 and 3. Figure 2 compares life expectancies by matching each of the three male and female period series (1976, 1991, 2006) with the corresponding cohort series; Figure 3 compares retirement expectancies. As one would anticipate, the cohort life expectancies are greater than the period ones over the whole of the age range for both males and females, and for all three period/cohort comparisons. By comparing Tables 1 and 2 our hypothetical 1976 50-year-old would find that life expectancy was three years greater if he/she used the cohort calculation. That, when combined with changes in participation rates, is reflected in an additional 3.8 years of retirement for a working male, 2.7 for a working female.

The period/cohort differences in life expectancies are greater for women than for men in 2006, implying some future reversal of the narrowing trend in the male/female gap shown in the period tables. That result is based, of course, on the medians of the projected probability distributions, as described earlier. We think it credible but emphasize that actual future male and female expectancies could lie elsewhere in their distributions, with corresponding alternative effects on the gap.

CSP 2010, 37.1-2: 175-206 
Table 2

Cohort Working Life Tables, Selected Ages for Male and Female Cohorts of Age 50, Medium Projection Assumptions for Canada: 1976, 1991 and 2006

\begin{tabular}{|c|c|c|c|c|c|c|c|c|c|c|c|c|}
\hline \multirow{2}{*}{$\begin{array}{c}\text { Cohort and } \\
\text { Variable }\end{array}$} & \multicolumn{6}{|c|}{ Males } & \multicolumn{6}{|c|}{ Females } \\
\hline & $x=50$ & $x=55$ & $x=60$ & $x=65$ & $x=70$ & $x=75$ & $\mathbf{x}=\mathbf{5 0}$ & $x=55$ & $x=60$ & $x=65$ & $x=70$ & $x=75$ \\
\hline \multicolumn{13}{|l|}{ Age 50 in 1976} \\
\hline l(x) & 100,000 & 95,854 & 90,272 & 82,898 & 73,460 & 61,687 & 100,000 & 97,870 & 94,918 & 90,867 & 85,249 & 77,328 \\
\hline$q(x)$ & 0.0073 & 0.0103 & 0.0147 & 0.0204 & 0.0300 & 0.0417 & 0.0038 & 0.0053 & 0.0075 & 0.0106 & 0.0162 & 0.0247 \\
\hline$e(x)$ & 27.9 & 23.9 & 20.3 & 16.8 & 13.7 & 10.8 & 33.5 & 29.2 & 25.0 & 21.0 & 17.2 & 13.7 \\
\hline $\mathbf{f}(\mathbf{x})$ & 94,625 & 81,435 & 63,232 & 24,375 & 8,074 & 3,939 & 50,314 & 43,140 & 31,217 & 11,766 & 3,833 & 1,528 \\
\hline$n(x)$ & 5,375 & 14,419 & 27,040 & 58,523 & 65,386 & 57,748 & 49,686 & 54,730 & 63,701 & 79,100 & 81,417 & 75,800 \\
\hline $\mathbf{p}(\mathbf{x})$ & 0.946 & 0.845 & 0.691 & 0.299 & 0.113 & 0.066 & 0.503 & 0.449 & 0.332 & 0.129 & 0.047 & 0.020 \\
\hline $\operatorname{ewl}(x)$ & 11.6 & 7.4 & 3.8 & 1.4 & 0.7 & 0.4 & 5.7 & 3.6 & 1.7 & 0.6 & 0.2 & 0.1 \\
\hline enl(x) & 16.3 & 16.5 & 16.5 & 15.4 & 13.0 & 10.4 & 27.8 & 25.6 & 23.3 & 20.4 & 17.0 & 13.6 \\
\hline enl/e(e $(x)$ & 0.585 & 0.689 & 0.812 & 0.915 & 0.948 & 0.965 & 0.829 & 0.878 & 0.933 & 0.972 & 0.986 & 0.991 \\
\hline $\mathbf{r}(\mathbf{x})$ & 0.033 & 0.023 & 0.141 & 0.285 & 0.106 & 0.040 & 0.050 & 0.020 & 0.126 & 0.271 & 0.176 & 0.090 \\
\hline $\operatorname{ewf}(x)$ & 12.2 & 8.8 & 5.4 & 4.9 & 6.4 & 5.9 & 11.4 & 8.1 & 5.1 & 4.5 & 5.5 & 6.0 \\
\hline $\operatorname{enf}(x)$ & 15.6 & 15.2 & 14.8 & 11.9 & 7.3 & 4.8 & 22.1 & 21.1 & 19.9 & 16.5 & 11.7 & 7.7 \\
\hline enf $/ \mathbf{e}(x)$ & 0.561 & 0.634 & 0.732 & 0.709 & 0.531 & 0.449 & 0.660 & 0.723 & 0.795 & 0.787 & 0.679 & 0.561 \\
\hline \multicolumn{13}{|l|}{ Age 50 in 1991} \\
\hline l(x) & 100,000 & 97,359 & 93,591 & 88,454 & 81,306 & 70,998 & 100,000 & 98,406 & 96,071 & 92,839 & 88,315 & 81,859 \\
\hline$q(x)$ & 0.0045 & 0.0067 & 0.0098 & 0.0135 & 0.0220 & 0.0355 & 0.0027 & 0.0041 & 0.0059 & 0.0085 & 0.0127 & 0.0198 \\
\hline$e(x)$ & 30.5 & 26.2 & 22.2 & 18.3 & 14.7 & 11.5 & 35.6 & 31.2 & 26.9 & 22.7 & 18.7 & 15.0 \\
\hline$f(x)$ & 91,133 & 77,821 & 56,015 & 32,146 & 11,465 & 5,280 & 71,923 & 55,968 & 37,585 & 19,087 & 5,715 & 1,825 \\
\hline $\mathrm{n}(\mathbf{x})$ & 8,867 & 19,538 & 37,576 & 56,308 & 69,841 & 65,718 & 28,077 & 42,439 & 58,486 & 73,752 & 82,600 & 80,034 \\
\hline $\mathbf{p}(\mathbf{x})$ & 0.911 & 0.800 & 0.603 & 0.368 & 0.141 & 0.074 & 0.719 & 0.574 & 0.403 & 0.209 & 0.065 & 0.022 \\
\hline $\operatorname{ewl}(x)$ & 11.4 & 7.4 & 4.1 & 1.8 & 0.8 & 0.4 & 7.8 & 4.7 & 2.3 & 0.9 & 0.3 & 0.1 \\
\hline $\operatorname{enl}(x)$ & 19.0 & 18.9 & 18.1 & 16.5 & 13.9 & 11.1 & 27.8 & 26.5 & 24.5 & 21.8 & 18.4 & 14.9 \\
\hline enl/e(x) & 0.625 & 0.719 & 0.815 & 0.900 & 0.945 & 0.964 & 0.782 & 0.850 & 0.913 & 0.961 & 0.984 & 0.991 \\
\hline $\mathbf{r}(\mathbf{x})$ & 0.018 & 0.047 & 0.108 & 0.223 & 0.180 & 0.034 & 0.040 & 0.059 & 0.111 & 0.269 & 0.201 & 0.160 \\
\hline $\operatorname{ewf}(x)$ & 12.6 & 9.2 & 6.8 & 5.0 & 5.8 & 5.5 & 10.8 & 8.2 & 6.0 & 4.3 & 4.8 & 5.7 \\
\hline $\operatorname{enf}(x)$ & 17.9 & 17.0 & 15.4 & 13.3 & 9.0 & 6.0 & 24.8 & 22.9 & 20.9 & 18.4 & 14.0 & 9.2 \\
\hline enf $/ \mathbf{e}(x)$ & 0.588 & 0.649 & 0.692 & 0.725 & 0.609 & 0.522 & 0.696 & 0.736 & 0.778 & 0.811 & 0.745 & 0.617 \\
\hline \multicolumn{13}{|l|}{ Age 50 in 2006} \\
\hline I(x) & 100,000 & 98,277 & 95,434 & 90,832 & 83,727 & 73,637 & 100,000 & 98,781 & 97,003 & 94,522 & 90,983 & 85,805 \\
\hline$q(x)$ & 0.0029 & 0.0047 & 0.0078 & 0.0128 & 0.0208 & 0.0334 & 0.0020 & 0.0029 & 0.0043 & 0.0067 & 0.0096 & 0.0145 \\
\hline$e(x)$ & 31.6 & 27.1 & 22.8 & 18.9 & 15.2 & 12.0 & 37.7 & 33.2 & 28.7 & 24.4 & 20.3 & 16.3 \\
\hline $\mathbf{f}(\mathbf{x})$ & 91,007 & 81,163 & 62,883 & 33,416 & 11,806 & 5,476 & 80,290 & 69,643 & 46,397 & 19,721 & 5,888 & 1,913 \\
\hline$n(x)$ & 8,993 & 17,114 & 32,550 & 57,416 & 71,920 & 68,160 & 19,710 & 29,138 & 50,606 & 74,801 & 85,096 & 83,896 \\
\hline $\mathbf{p}(\mathbf{x})$ & 0.910 & 0.826 & 0.659 & 0.368 & 0.141 & 0.074 & 0.803 & 0.705 & 0.478 & 0.209 & 0.065 & 0.022 \\
\hline $\operatorname{ewl}(x)$ & 12.0 & 7.8 & 4.3 & 1.8 & 0.8 & 0.4 & 9.2 & 5.5 & 2.6 & 0.9 & 0.3 & 0.1 \\
\hline enl(x) & 19.6 & 19.3 & 18.6 & 17.0 & 14.4 & 11.5 & 28.5 & 27.6 & 26.1 & 23.5 & 19.9 & 16.2 \\
\hline enl $/(\mathbf{e}(\mathbf{x})$ & 0.620 & 0.711 & 0.813 & 0.902 & 0.946 & 0.965 & 0.756 & 0.834 & 0.910 & 0.963 & 0.984 & 0.992 \\
\hline $\mathbf{r}(\mathbf{x})$ & 0.014 & 0.036 & 0.073 & 0.232 & 0.181 & 0.035 & 0.015 & 0.051 & 0.113 & 0.280 & 0.202 & 0.160 \\
\hline $\operatorname{ewf}(x)$ & 13.2 & 9.5 & 6.5 & 5.0 & 5.8 & 5.6 & 11.5 & 7.8 & 5.4 & 4.3 & 4.9 & 5.9 \\
\hline $\operatorname{enf}(x)$ & 18.4 & 17.6 & 16.3 & 13.8 & 9.4 & 6.4 & 26.2 & 25.3 & 23.3 & 20.1 & 15.4 & 10.4 \\
\hline enf/e(x) & 0.583 & 0.651 & 0.716 & 0.734 & 0.617 & 0.532 & 0.696 & 0.764 & 0.811 & 0.824 & 0.759 & 0.637 \\
\hline
\end{tabular}

CSP 2010, 37.1-2: 175-206 
Figure 2

Comparisons of Period Life Expectancies (e(x)) for Canada in 1976, 1991 and 2006 with Cohort Life Expectancies for Cohorts of Age 50 in the Corresponding Years (medium projection assumptions)
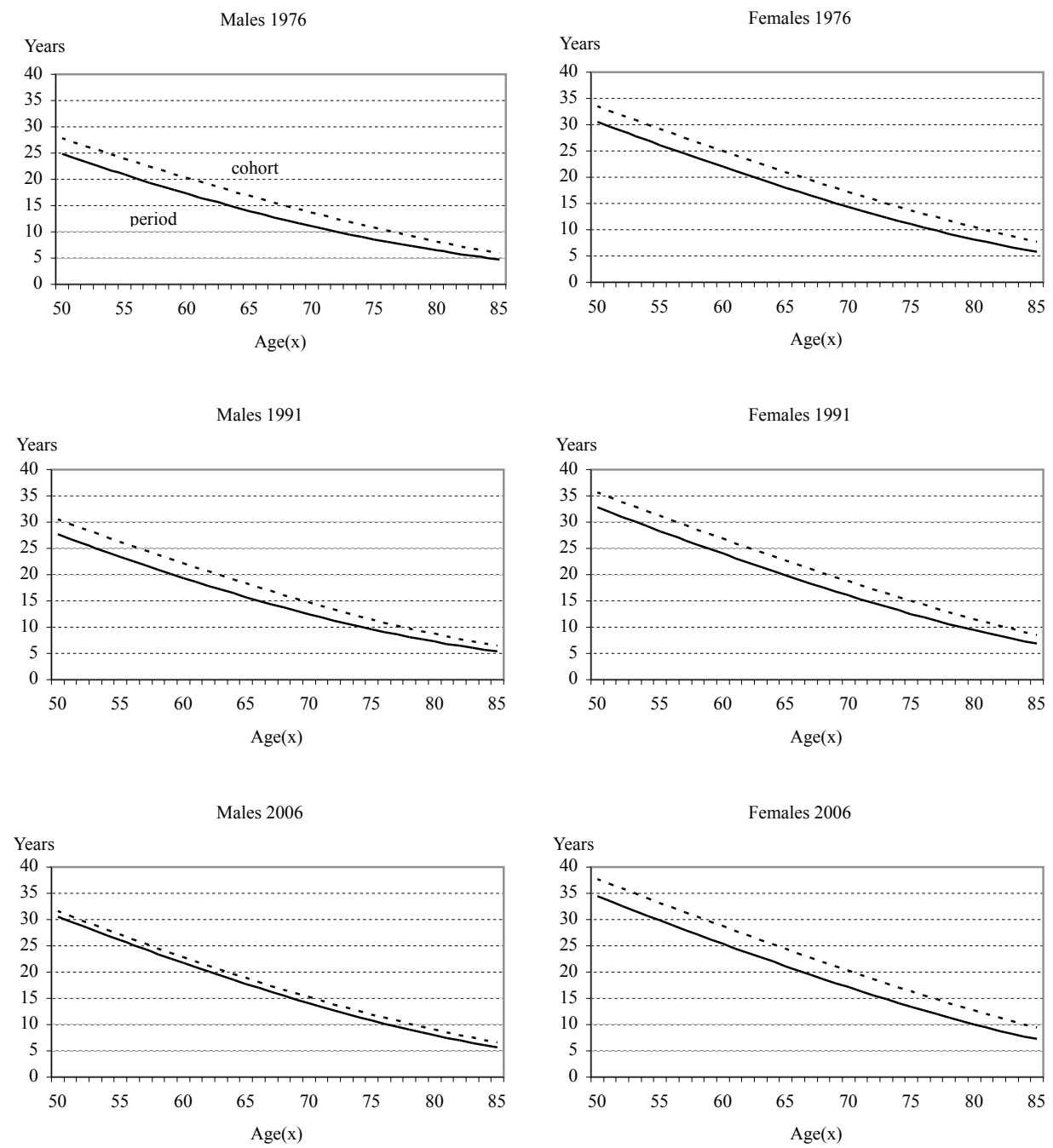

CSP 2010, 37.1-2: 175-206 
Figure 3

Comparisons of Period Retirement Expectancies (enf(x)) for Canada in 1976, 1991 and 2006 with Cohort Life Retirement Expectancies for Cohorts of Age 50 in the Corresponding Years (medium projection assumptions)
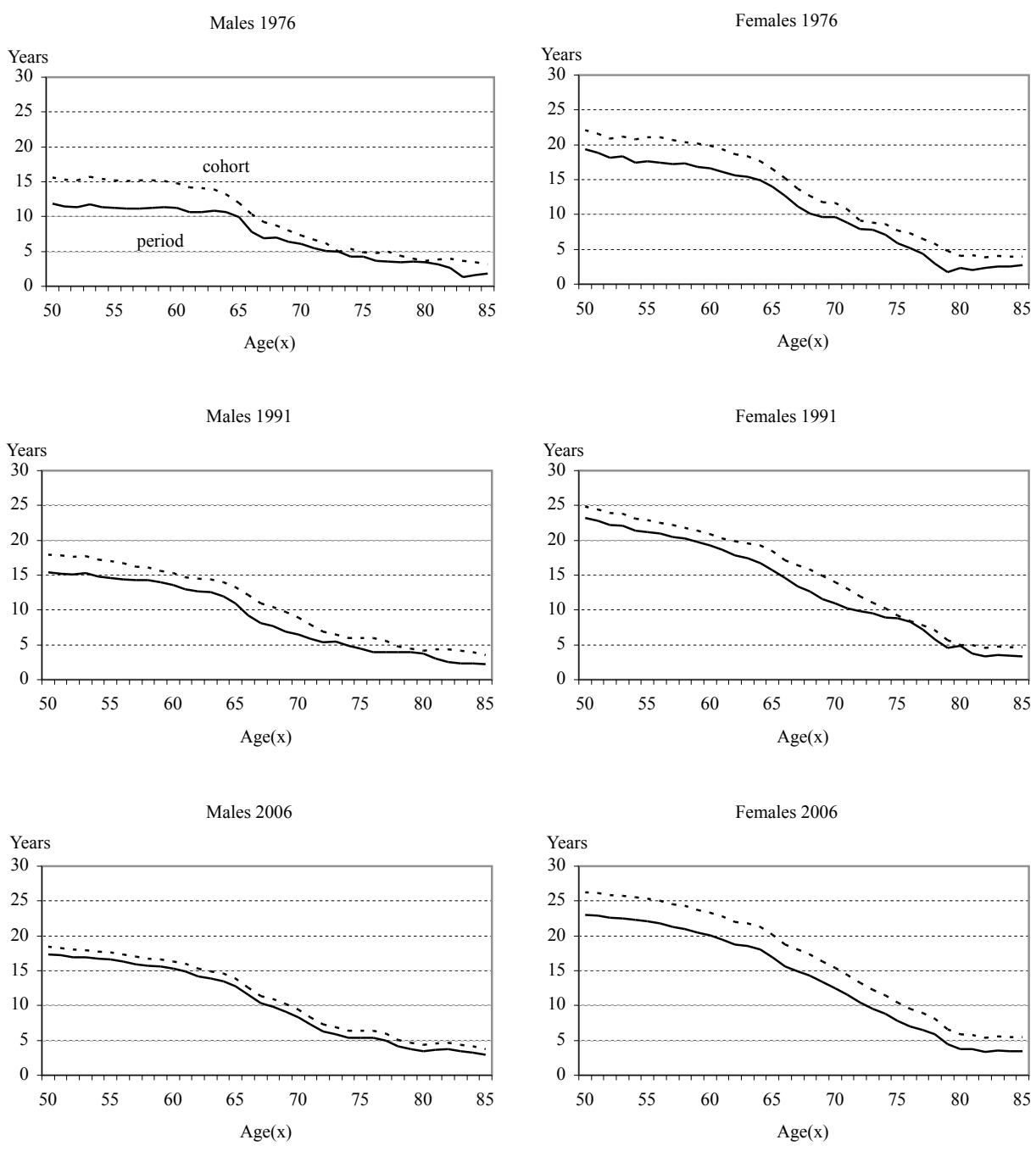
Similar results hold for retirement expectancies. The 50-in-2006 cohort series are based entirely on the medium projections of life expectancy and the assumption of constant participation rates. On that basis, women could expect a greater increase in retirement expectancy than men by virtue of their larger increases in life expectancy; the differences between the period and cohort series are greater for women, as seen in Figure 3. "Assumption" is of course a key word here. It is possible that future participation rates of women will change, and patterns of retirement accordingly, although they would have to change greatly in order for this result to be overturned in any major way, as the discussion below suggests.

The separate contributions of changes in participation and death rates to the differences between period and cohort working life expectancies can be investigated by another set of calculations. For the 2006 male and female cohorts the medium projections assume no change in participation rates after 2006 so the period/cohort differences are attributable entirely to death rate differences. For the 1991 cohorts the participation rates are actual ones from age 50 to age 65 , no-change projections beyond that. For the 1976 cohorts the rates are actual up to age 80; the effects of the projections are therefore negligible for those cohorts.

With the foregoing in mind we have redone the cohort calculations of Table 2, keeping the same death rates as before but this time holding participation rates constant at their initial levels - at the 1991 levels for the 1991 cohorts, the 1976 levels for the 1976 cohorts. The results are shown in Table 3. We show calculations for the 2006 cohorts in Table 3 also but those are unchanged from Table 2. Differences between the period calculations of Table 1 and the Table 3 cohort calculations are thus attributable entirely to changes in death rates. Differences between Table 1 and Table 2, on the other hand, reflect both changes in death rates and changes in participation rates. By implication, then, subtracting the Table 3 / Table 1 differences from the Table 2 / Table 1 differences gives the pure effects of participation rate changes. Strictly speaking, there is an unassignable component of the Table $2 /$ Table 1 differences, representing the interaction of participation rate changes and death rate changes, but that is negligible.

We focus on the 1976 male and female cohorts, the ones for which the projections after 2006 have hardly any effect. More specifically, we focus on the working life expectancies for people in those cohorts. A male of age 50 in the working population in 1976 would have had a working life expectancy (ewf) of 13.0 years, according to the period calculations of Table 1 , and of 12.2 years according to the cohort calculations of Table 2 , a difference of -0.8 years. If the effects of participation rate changes are removed (Table 3 ), the cohort working life expectancy increases to 13.3 years and the period/cohort difference is now 0.3. The declines in death rates thus had the effect of lengthening the average 
Table 3

Cohort Working Life Tables, Selected Ages for Male and Female Cohorts of Age 50, Medium Projection Assumptions, with Labour Force Participation Rates held Constant for Canada: 1976, 1991 and 2006

\begin{tabular}{|c|c|c|c|c|c|c|c|c|c|c|c|c|}
\hline \multirow{2}{*}{$\begin{array}{c}\text { Cohort and } \\
\text { Variable }\end{array}$} & \multicolumn{6}{|c|}{ Males } & \multicolumn{6}{|c|}{ Females } \\
\hline & $\mathbf{x}=\mathbf{5 0}$ & $x=55$ & $x=60$ & $x=65$ & $x=70$ & $x=75$ & $\mathbf{x}=\mathbf{5 0}$ & $x=55$ & $x=60$ & $x=65$ & $x=70$ & $x=75$ \\
\hline \multicolumn{13}{|l|}{$\underline{\text { Age } 50 \text { in } 1976}$} \\
\hline I(x) & 100,000 & 95,854 & 90,272 & 82,898 & 73,460 & 61,687 & 100,000 & 97,870 & 94,918 & 90,867 & 85,249 & 77,328 \\
\hline$q(x)$ & 0.0073 & 0.0103 & 0.0147 & 0.0204 & 0.0300 & 0.0417 & 0.0038 & 0.0053 & 0.0075 & 0.0106 & 0.0162 & 0.0247 \\
\hline$e(x)$ & 27.9 & 23.9 & 20.3 & 16.8 & 13.7 & 10.8 & 33.5 & 29.2 & 25.0 & 21.0 & 17.2 & 13.7 \\
\hline$f(x)$ & 94,625 & 82,238 & 69,242 & 36,732 & 11,917 & 5,258 & 50,314 & 40,090 & 30,438 & 13,297 & 4,149 & 1,388 \\
\hline$n(x)$ & 5,375 & 13,616 & 21,031 & 46,166 & 61,543 & 56,429 & 49,686 & 57,779 & 64,480 & 77,570 & 81,100 & 75,940 \\
\hline$p(x)$ & 0.946 & 0.845 & 0.691 & 0.299 & 0.113 & 0.066 & 0.503 & 0.449 & 0.332 & 0.129 & 0.047 & 0.020 \\
\hline ewl(x) & 12.6 & 8.5 & 4.8 & 1.9 & 0.9 & 0.4 & 5.6 & 3.5 & 1.7 & 0.6 & 0.2 & 0.1 \\
\hline enl(x) & 15.3 & 15.4 & 15.5 & 14.9 & 12.8 & 10.4 & 27.9 & 25.7 & 23.3 & 20.4 & 17.0 & 13.6 \\
\hline enl/e(x) & 0.548 & 0.644 & 0.763 & 0.886 & 0.935 & 0.962 & 0.831 & 0.880 & 0.931 & 0.971 & 0.986 & 0.993 \\
\hline $\mathbf{r}(\mathbf{x})$ & 0.033 & 0.022 & 0.117 & 0.381 & 0.152 & 0.177 & 0.050 & 0.041 & 0.116 & 0.304 & 0.189 & 0.162 \\
\hline $\operatorname{ewf}(x)$ & 13.3 & 9.9 & 6.3 & 4.3 & 5.5 & 4.8 & 11.2 & 8.6 & 5.4 & 4.1 & 5.0 & 5.6 \\
\hline $\operatorname{enf}(x)$ & 14.5 & 14.0 & 14.0 & 12.5 & 8.2 & 6.0 & 22.3 & 20.6 & 19.6 & 16.9 & 12.2 & 8.1 \\
\hline enf $/$ e(x) & 0.522 & 0.585 & 0.691 & 0.742 & 0.600 & 0.553 & 0.665 & 0.706 & 0.784 & 0.805 & 0.708 & 0.589 \\
\hline \multicolumn{13}{|l|}{ Age 50 in 1991} \\
\hline I(x) & 100,000 & 97,359 & 93,591 & 88,454 & 81,306 & 70,998 & 100,000 & 98,406 & 96,071 & 92,839 & 88,315 & 81,859 \\
\hline$q(x)$ & 0.0045 & 0.0067 & 0.0098 & 0.0135 & 0.0220 & 0.0355 & 0.0027 & 0.0041 & 0.0059 & 0.0085 & 0.0127 & 0.0198 \\
\hline$e(x)$ & 30.5 & 26.2 & 22.2 & 18.3 & 14.7 & 11.5 & 35.6 & 31.2 & 26.9 & 22.7 & 18.7 & 15.0 \\
\hline $\mathbf{f}(\mathbf{x})$ & 91,133 & 78,959 & 59,136 & 26,434 & 9,466 & 4,728 & 71,923 & 53,137 & 33,846 & 11,933 & 3,453 & 1,632 \\
\hline $\mathrm{n}(\mathrm{x})$ & 8,867 & 18,400 & 34,456 & 62,021 & 71,839 & 66,270 & 28,077 & 45,269 & 62,225 & 80,906 & 84,862 & 80,227 \\
\hline $\mathbf{p}(\mathbf{x})$ & 0.911 & 0.800 & 0.603 & 0.368 & 0.141 & 0.074 & 0.719 & 0.574 & 0.403 & 0.209 & 0.065 & 0.022 \\
\hline $\operatorname{ewl}(x)$ & 11.4 & 7.2 & 3.8 & 1.5 & 0.7 & 0.4 & 7.0 & 3.9 & 1.7 & 0.5 & 0.2 & 0.1 \\
\hline enl(x) & 19.1 & 19.0 & 18.4 & 16.8 & 14.0 & 11.1 & 28.7 & 27.3 & 25.2 & 22.2 & 18.5 & 14.9 \\
\hline enl/e(x) & 0.628 & 0.724 & 0.831 & 0.917 & 0.949 & 0.967 & 0.805 & 0.875 & 0.938 & 0.976 & 0.989 & 0.995 \\
\hline $\mathbf{r}(\mathbf{x})$ & 0.018 & 0.038 & 0.133 & 0.299 & 0.130 & 0.126 & 0.040 & 0.044 & 0.146 & 0.266 & 0.158 & 0.191 \\
\hline $\operatorname{ewf}(x)$ & 12.5 & 8.9 & 5.9 & 5.1 & 6.4 & 5.6 & 9.7 & 7.2 & 4.8 & 4.2 & 5.3 & 3.9 \\
\hline $\operatorname{enf}(x)$ & 18.0 & 17.3 & 16.3 & 13.2 & 8.3 & 5.9 & 26.0 & 24.0 & 22.1 & 18.5 & 13.5 & 11.1 \\
\hline enf/e(x) & 0.591 & 0.660 & 0.732 & 0.722 & 0.563 & 0.511 & 0.729 & 0.769 & 0.823 & 0.814 & 0.719 & 0.743 \\
\hline \multicolumn{13}{|l|}{ Age 50 in 2006} \\
\hline I(x) & 100,000 & 98,277 & 95,434 & 90,832 & 83,727 & 73,637 & 100,000 & 98,781 & 97,003 & 94,522 & 90,983 & 85,809 \\
\hline$q(x)$ & 0.0029 & 0.0047 & 0.0078 & 0.0128 & 0.0208 & 0.0334 & 0.0020 & 0.0029 & 0.0043 & 0.0067 & 0.0096 & 0.0149 \\
\hline$e(x)$ & 31.6 & 27.1 & 22.8 & 18.9 & 15.2 & 12.0 & 37.7 & 33.2 & 28.7 & 24.4 & 20.3 & 16.3 \\
\hline $\mathbf{f}(\mathbf{x})$ & 91,007 & 81,163 & 62,883 & 33,416 & 11,806 & 5,476 & 80,290 & 69,643 & 46,397 & 19,721 & 5,888 & 1,913 \\
\hline$n(x)$ & 8,993 & 17,114 & 32,550 & 57,416 & 71,920 & 68,160 & 19,710 & 29,138 & 50,606 & 74,801 & 85,096 & 83,896 \\
\hline $\mathbf{p}(\mathbf{x})$ & 0.910 & 0.826 & 0.659 & 0.368 & 0.141 & 0.074 & 0.803 & 0.705 & 0.478 & 0.209 & 0.065 & 0.022 \\
\hline $\operatorname{ewl}(x)$ & 12.0 & 7.8 & 4.3 & 1.8 & 0.8 & 0.4 & 9.2 & 5.5 & 2.6 & 0.9 & 0.3 & 0.1 \\
\hline enl(x) & 19.6 & 19.3 & 18.6 & 17.0 & 14.4 & 11.5 & 28.5 & 27.6 & 26.1 & 23.5 & 19.9 & 16.2 \\
\hline enl/e(x) & 0.620 & 0.711 & 0.813 & 0.902 & 0.946 & 0.965 & 0.756 & 0.834 & 0.910 & 0.963 & 0.984 & 0.992 \\
\hline $\mathbf{r}(\mathbf{x})$ & 0.014 & 0.036 & 0.073 & 0.232 & 0.181 & 0.035 & 0.015 & 0.051 & 0.113 & 0.280 & 0.202 & 0.160 \\
\hline $\operatorname{ewf}(x)$ & 13.2 & 9.5 & 6.5 & 5.0 & 5.8 & 5.6 & 11.5 & 7.8 & 5.4 & 4.3 & 4.9 & 5.9 \\
\hline $\operatorname{enf}(x)$ & 18.4 & 17.6 & 16.3 & 13.8 & 9.4 & 6.4 & 26.2 & 25.3 & 23.3 & 20.1 & 15.4 & 10.4 \\
\hline enf/e(x) & 0.583 & 0.651 & 0.716 & 0.734 & 0.617 & 0.532 & 0.696 & 0.764 & 0.811 & 0.824 & 0.759 & 0.637 \\
\hline
\end{tabular}

CSP 2010, 37.1-2: 175-206 
working life by 0.3 years while declines in participation rates had the effect of reducing it by 1.1 , leaving as the net effect a reduction of 0.8 . The effects were therefore offsetting but the participation rate effect was dominant for males.

For females there was hardly any effect at all - an increase of 0.3 years when cohort calculations replace period calculations, with lower death rates contributing 0.1 years, higher participation rates 0.2 years. To put it differently, most of the gains in life expectancy were taken in the form of additional years of retirement. The male retirement expectancy (enf) rose by 3.8 years, of which 2.7 can be attributed to increased life expectancy. The female retirement expectancy rose by 2.7 years: 2.9 years attributable to increased life expectancy with an offset of only -0.2 from increased participation. To look at things from another angle, the difference in working life expectancy for men and women who were in the labour force at age 50 narrows when cohort calculations are used instead of period calculations - from a difference of 1.9 years in favour of males, to 0.8 years - and the retirement expectancy difference narrows also - from 7.6 in favour of females, to 6.5 .

\section{Sensitivity to Projections}

An obvious question is how sensitive are the male and female cohort working life tables to differences in projection assumptions. The 50-in-1976 cohorts are necessarily quite insensitive since they are already 80 by the time projections are needed to complete their life paths. One would expect the 50-in-1991 cohorts to be more sensitive and the 50-in-2006 cohorts to be the most sensitive of all, since the whole of their post-50 life paths must be based on projections. We explore the issue of sensitivity in Tables 4 and 5 by recalculating the working life tables for the latter two pairs of cohorts using different combinations of life expectancy and participation rate assumptions for the years after 2006. The alternatives are coded $\mathrm{M}$ for medium, $\mathrm{H}$ and $\mathrm{L}$ for high and low, with definitions as given in earlier sections. Combinations are coded with two letters, the first standing for life expectancy, the second for participation rate; MH stands for medium life expectancy projection combined with high participation, for example. Six variables are shown in the tables at ages 50,55 , etc., up to 75 , as in the previous ones. We focus mainly on the 50-in-2006 cohort results in Table 5, since the 2006 cohorts are the most sensitive to the choice of projection assumptions.

The high/low range of life expectancy at age 50 in Table 5 is 1.9 years for males (30.9 to 32.8) and 2.4 years for females (36.3 to 38.7). The results reflect the slightly greater uncertainty about the future mortality rates of women but a difference of half a year must be viewed as small, given that the projections must go out as far as 2064 in order to complete the 50-in-2006 cohort life spans. A rough generalization for both sexes would be that using the high projection

CSP 2010, 37.1-2: 175-206 
adds about two years to life expectancy at age 50 compared with the low projection, and about a year compared with the medium projection.

Holding life expectancy at its medium level and allowing the participation rate assumptions to be at one extreme or the other (MH compared with ML) makes a difference of 1.7 years in both working life expectancy and retirement expectancy $(\operatorname{ewf}(\mathrm{x})$ and $\operatorname{enf}(\mathrm{x}))$ for males who were in the labour force at age 50, and a year for those still in the labour force at age 60. For females the difference is about a year and a half at 50, a year at 60 . Combining high life expectancy with high participation or low life expectancy with low participation has only a small further effect on the ranges. The projection assumptions do make some difference in going from one extreme to another but the differences in work/retirement patterns are generally small. Keep in mind that we are considering here the 50-in-2006 cohorts, the ones for which all of the post-50 life paths must be projected. For the 50 -in-1991 cohorts the differences resulting from the choice of participation assumptions range from small to negligible, as shown in Table 4.

Our overall assessment of the sensitivity of the working life tables to projection assumptions is that the choice of assumptions does make some difference but the differences are generally of small order. Patterns of life expectancy, and more especially work/retirement patterns, are fairly robust to the choice.

\section{Conclusion}

We have constructed period working life tables and what we believe to be the first published set of cohort working life tables for older Canadian men and women. In doing so we have made use of recently available Labour Force Survey master files, containing data by single years of age, and methods of stochastic mortality projection developed by us in earlier work. Our population of interest has been the population 50 years of age and older and our focus the life expectancy and retirement patterns of that population. We have given special attention to tables for the years 1976, 1991, and 2006, thus spanning a period of three decades. These tables reflect the gains in length of life that have taken place over that period, the historic rise in the labour force participation rates of women, and the associated trends in work and retirement. The effects of increased life expectancy on the number of years after withdrawal from the labour force are evident from the period tables but more accurately, we believe, from the cohort tables. The differential effects of life expectancy on male and female retirement expectancies are of particular note.

Consistent with other research, and reflecting the continued declines in mortality rates, we find that cohort life expectancy exceeds period life expectancy. The difference varies somewhat from one cohort to another, but for

CSP 2010, 37.1-2: 175-206 
Table 4

Cohort Working Life Expectancies for Males and Females of Selected Ages, Alternative Projection Assumptions, Cohorts of Age 50 for Canada: 1991

\begin{tabular}{|c|c|c|c|c|c|c|c|c|c|c|c|c|c|}
\hline \multirow{2}{*}{$\begin{array}{c}\text { Projection } \\
\text { Assumption }\end{array}$} & \multirow{2}{*}{ Variable } & \multicolumn{6}{|c|}{ Males } & \multicolumn{6}{|c|}{ Females } \\
\hline & & $\mathbf{x}=\mathbf{5 0}$ & $x=55$ & $x=60$ & $x=65$ & $x=70$ & $x=75$ & $\mathbf{x}=\mathbf{5 0}$ & $x=55$ & $x=60$ & $x=65$ & $x=70$ & $x=75$ \\
\hline \multirow[t]{6}{*}{ MM } & $e(x)$ & 30.5 & 26.2 & 22.2 & 18.3 & 14.7 & 11.5 & 35.6 & 31.2 & 26.9 & 22.7 & 18.7 & 15.0 \\
\hline & $\mathbf{p}(\mathbf{x})$ & 0.911 & 0.800 & 0.603 & 0.368 & 0.141 & 0.074 & 0.719 & 0.574 & 0.403 & 0.209 & 0.065 & 0.022 \\
\hline & ewl(x) & 11.4 & 7.4 & 4.1 & 1.8 & 0.8 & 0.4 & 7.8 & 4.7 & 2.3 & 0.9 & 0.3 & 0.1 \\
\hline & enl(x) & 19.0 & 18.9 & 18.1 & 16.5 & 13.9 & 11.1 & 27.8 & 26.5 & 24.5 & 21.8 & 18.4 & 14.9 \\
\hline & ewf(x) & 12.6 & 9.2 & 6.8 & 5.0 & 5.8 & 5.5 & 10.8 & 8.2 & 6.0 & 4.3 & 4.8 & 5.7 \\
\hline & $\operatorname{enf}(x)$ & 17.9 & 17.0 & 15.4 & 13.3 & 9.0 & 6.0 & 24.8 & 22.9 & 20.9 & 18.4 & 14.0 & 9.2 \\
\hline \multirow[t]{6}{*}{ MH } & $e(x)$ & 30.5 & 26.2 & 22.2 & 18.3 & 14.7 & 11.5 & 35.6 & 31.2 & 26.9 & 22.7 & 18.7 & 15.0 \\
\hline & $\mathbf{p}(\mathbf{x})$ & 0.911 & 0.800 & 0.603 & 0.368 & 0.154 & 0.074 & 0.719 & 0.574 & 0.403 & 0.209 & 0.084 & 0.022 \\
\hline & ewl(x) & 11.5 & 7.4 & 4.1 & 1.9 & 0.8 & 0.4 & 7.8 & 4.7 & 2.4 & 0.9 & 0.3 & 0.1 \\
\hline & enl(x) & 19.0 & 18.8 & 18.1 & 16.5 & 13.9 & 11.1 & 27.8 & 26.4 & 24.4 & 21.7 & 18.4 & 14.9 \\
\hline & ewf(x) & 12.6 & 9.3 & 6.9 & 5.2 & 5.6 & 5.5 & 10.9 & 8.3 & 6.1 & 4.6 & 4.3 & 5.8 \\
\hline & $\operatorname{enf}(x)$ & 17.9 & 17.0 & 15.3 & 13.2 & 9.1 & 6.0 & 24.7 & 22.8 & 20.7 & 18.1 & 14.4 & 9.2 \\
\hline \multirow[t]{6}{*}{ ML } & $\mathbf{e}(\mathbf{x})$ & 30.5 & 26.2 & 22.2 & 18.3 & 14.7 & 11.5 & 35.6 & 31.2 & 26.9 & 22.7 & 18.7 & 15.0 \\
\hline & $\mathbf{p}(\mathbf{x})$ & 0.911 & 0.800 & 0.603 & 0.368 & 0.128 & 0.074 & 0.719 & 0.574 & 0.403 & 0.209 & 0.065 & 0.022 \\
\hline & ewl(x) & 11.4 & 7.3 & 4.0 & 1.8 & 0.8 & 0.4 & 7.8 & 4.7 & 2.3 & 0.9 & 0.3 & 0.1 \\
\hline & enl(x) & 19.1 & 18.9 & 18.1 & 16.6 & 13.9 & 11.1 & 27.8 & 26.5 & 24.5 & 21.8 & 18.4 & 14.9 \\
\hline & ewf(x) & 12.5 & 9.2 & 6.8 & 4.9 & 5.9 & 5.5 & 10.8 & 8.2 & 6.0 & 4.3 & 4.8 & 5.8 \\
\hline & $\operatorname{enf}(x)$ & 18.0 & 17.1 & 15.4 & 13.4 & 8.8 & 6.0 & 24.8 & 22.9 & 20.9 & 18.4 & 14.0 & 9.2 \\
\hline \multirow[t]{6}{*}{ HM } & $e(x)$ & 30.7 & 26.5 & 22.5 & 18.6 & 14.9 & 11.6 & 36.3 & 31.9 & 27.6 & 23.5 & 19.5 & 15.8 \\
\hline & $\mathbf{p}(\mathbf{x})$ & 0.911 & 0.800 & 0.603 & 0.368 & 0.141 & 0.074 & 0.719 & 0.574 & 0.403 & 0.209 & 0.065 & 0.022 \\
\hline & $\operatorname{ewl}(x)$ & 11.5 & 7.4 & 4.1 & 1.8 & 0.8 & 0.4 & 7.8 & 4.7 & 2.3 & 0.9 & 0.3 & 0.1 \\
\hline & enl(x) & 19.3 & 19.1 & 18.3 & 16.8 & 14.1 & 11.2 & 28.6 & 27.2 & 25.3 & 22.6 & 19.2 & 15.7 \\
\hline & $\operatorname{ewf}(x)$ & 12.6 & 9.2 & 6.9 & 5.1 & 5.8 & 5.6 & 10.8 & 8.2 & 6.0 & 4.3 & 4.8 & 5.8 \\
\hline & $\operatorname{enf}(x)$ & 18.2 & 17.3 & 15.6 & 13.5 & 9.1 & 6.0 & 25.5 & 23.7 & 21.6 & 19.2 & 14.7 & 10.0 \\
\hline \multirow[t]{6}{*}{$\mathbf{L M}$} & $e(x)$ & 30.0 & 25.7 & 21.7 & 17.8 & 14.1 & 10.9 & 34.6 & 30.2 & 25.8 & 21.6 & 17.7 & 14.0 \\
\hline & $\mathbf{p}(\mathbf{x})$ & 0.911 & 0.800 & 0.603 & 0.368 & 0.141 & 0.074 & 0.719 & 0.574 & 0.403 & 0.209 & 0.065 & 0.022 \\
\hline & ewl(x) & 11.4 & 7.4 & 4.1 & 1.8 & 0.8 & 0.4 & 7.8 & 4.7 & 2.3 & 0.9 & 0.3 & 0.1 \\
\hline & enl(x) & 18.6 & 18.4 & 17.6 & 16.0 & 13.3 & 10.5 & 26.9 & 25.5 & 23.5 & 20.8 & 17.4 & 13.8 \\
\hline & ewf(x) & 12.6 & 9.2 & 6.8 & 5.0 & 5.7 & 5.4 & 10.8 & 8.2 & 6.0 & 4.3 & 4.7 & 5.6 \\
\hline & $\operatorname{enf}(x)$ & 17.5 & 16.5 & 14.8 & 12.8 & 8.4 & 5.5 & 23.8 & 22.0 & 19.9 & 17.4 & 13.0 & 8.3 \\
\hline \multirow[t]{6}{*}{ HH } & $e(x)$ & 30.7 & 26.5 & 22.5 & 18.6 & 14.9 & 11.6 & 36.3 & 31.9 & 27.6 & 23.5 & 19.5 & 15.8 \\
\hline & $\mathbf{p}(\mathbf{x})$ & 0.911 & 0.800 & 0.603 & 0.368 & 0.154 & 0.074 & 0.719 & 0.574 & 0.403 & 0.209 & 0.084 & 0.022 \\
\hline & ewl(x) & 11.5 & 7.4 & 4.2 & 1.9 & 0.9 & 0.4 & 7.8 & 4.7 & 2.4 & 1.0 & 0.3 & 0.1 \\
\hline & enl(x) & 19.2 & 19.1 & 18.3 & 16.7 & 14.1 & 11.2 & 28.5 & 27.2 & 25.2 & 22.5 & 19.2 & 15.7 \\
\hline & ewf(x) & 12.6 & 9.3 & 6.9 & 5.2 & 5.7 & 5.6 & 10.9 & 8.3 & 6.1 & 4.6 & 4.4 & 5.9 \\
\hline & $\operatorname{enf}(x)$ & 18.1 & 17.2 & 15.5 & 13.4 & 9.3 & 6.0 & 25.4 & 23.6 & 21.5 & 18.8 & 15.2 & 9.9 \\
\hline \multirow[t]{6}{*}{ LL } & e(x) & 30.0 & 25.7 & 21.7 & 17.8 & 14.1 & 10.9 & 34.6 & 30.2 & 25.8 & 21.6 & 17.7 & 14.0 \\
\hline & $\mathbf{p}(\mathbf{x})$ & 0.911 & 0.800 & 0.603 & 0.368 & 0.128 & 0.074 & 0.719 & 0.574 & 0.403 & 0.209 & 0.065 & 0.022 \\
\hline & ewl(x) & 11.4 & 7.3 & 4.0 & 1.8 & 0.8 & 0.4 & 7.8 & 4.7 & 2.3 & 0.9 & 0.3 & 0.1 \\
\hline & enl(x) & 18.6 & 18.4 & 17.6 & 16.0 & 13.4 & 10.5 & 26.9 & 25.5 & 23.5 & 20.8 & 17.4 & 13.8 \\
\hline & ewf(x) & 12.5 & 9.1 & 6.7 & 4.9 & 5.9 & 5.4 & 10.8 & 8.2 & 6.0 & 4.3 & 4.7 & 5.7 \\
\hline & $\operatorname{enf}(x)$ & 17.5 & 16.6 & 14.9 & 12.9 & 8.3 & 5.5 & 23.8 & 22.0 & 19.9 & 17.4 & 13.0 & 8.3 \\
\hline
\end{tabular}

Note: Life expectancy and participation rate projection assumptions are coded $\mathrm{M}$ for medium, $\mathrm{H}$ for high, $\mathrm{L}$ for low, with life expectancy given first, participation rate second. For example, $\mathrm{MH}$ stands for medium life expectancy, high participation rate.

CSP 2010, 37.1-2: 175-206 
Table 5

Cohort Working Life Expectancies for Males and Females of Selected Ages, Alternative Projection Assumptions, Cohorts of Age 50 for Canada: 2006

\begin{tabular}{|c|c|c|c|c|c|c|c|c|c|c|c|c|c|}
\hline \multirow{2}{*}{$\begin{array}{c}\text { Projection } \\
\text { Assumption }\end{array}$} & \multirow{2}{*}{ Variable } & \multicolumn{6}{|c|}{ Males } & \multicolumn{6}{|c|}{ Females } \\
\hline & & $\mathbf{x}=\mathbf{5 0}$ & $x=55$ & $x=60$ & $x=65$ & $x=70$ & $x=75$ & $\mathbf{x}=\mathbf{5 0}$ & $x=55$ & $x=60$ & $x=65$ & $x=70$ & $x=75$ \\
\hline \multirow[t]{6}{*}{ MM } & $\mathrm{e}(\mathrm{x})$ & 31.6 & 27.1 & 22.8 & 18.9 & 15.2 & 12.0 & 37.7 & 33.2 & 28.7 & 24.4 & 20.3 & 16.3 \\
\hline & $\mathrm{p}(\mathrm{x})$ & 0.910 & 0.826 & 0.659 & 0.368 & 0.141 & 0.074 & 0.803 & 0.705 & 0.478 & 0.209 & 0.065 & 0.022 \\
\hline & ewl(x) & 12.0 & 7.8 & 4.3 & 1.8 & 0.8 & 0.4 & 9.2 & 5.5 & 2.6 & 0.9 & 0.3 & 0.1 \\
\hline & $\mathrm{enl}(\mathrm{x})$ & 19.6 & 19.3 & 18.6 & 17.0 & 14.4 & 11.5 & 28.5 & 27.6 & 26.1 & 23.5 & 19.9 & 16.2 \\
\hline & ewf(x) & 13.2 & 9.5 & 6.5 & 5.0 & 5.8 & 5.6 & 11.5 & 7.8 & 5.4 & 4.3 & 4.9 & 5.9 \\
\hline & $\operatorname{enf}(x)$ & 18.4 & 17.6 & 16.3 & 13.8 & 9.4 & 6.4 & 26.2 & 25.3 & 23.3 & 20.1 & 15.4 & 10.4 \\
\hline \multirow[t]{6}{*}{$\mathrm{MH}$} & $e(x)$ & 31.6 & 27.1 & 22.8 & 18.9 & 15.2 & 12.0 & 37.7 & 33.2 & 28.7 & 24.4 & 20.3 & 16.3 \\
\hline & $\mathrm{p}(\mathrm{x})$ & 0.910 & 0.834 & 0.713 & 0.425 & 0.191 & 0.074 & 0.803 & 0.736 & 0.569 & 0.329 & 0.141 & 0.022 \\
\hline & ewl $(x)$ & 12.8 & 8.6 & 4.9 & 2.2 & 0.9 & 0.4 & 10.5 & 6.7 & 3.6 & 1.4 & 0.4 & 0.1 \\
\hline & enl(x) & 18.8 & 18.5 & 17.9 & 16.7 & 14.3 & 11.5 & 27.2 & 26.4 & 25.1 & 23.0 & 19.8 & 16.2 \\
\hline & ewf(x) & 14.0 & 10.3 & 7.0 & 5.1 & 5.0 & 5.6 & 13.1 & 9.2 & 6.4 & 4.5 & 3.3 & 6.0 \\
\hline & enf(x) & 17.6 & 16.8 & 15.9 & 13.7 & 10.2 & 6.3 & 24.7 & 23.9 & 22.3 & 19.9 & 17.0 & 10.3 \\
\hline \multirow[t]{6}{*}{ ML } & $\mathrm{e}(\mathrm{x})$ & 31.6 & 27.1 & 22.8 & 18.9 & 15.2 & 12.0 & 37.7 & 33.2 & 28.7 & 24.4 & 20.3 & 16.3 \\
\hline & $\mathrm{p}(\mathrm{x})$ & 0.910 & 0.818 & 0.605 & 0.311 & 0.091 & 0.074 & 0.803 & 0.705 & 0.478 & 0.209 & 0.065 & 0.022 \\
\hline & ewl(x) & 11.2 & 7.1 & 3.6 & 1.5 & 0.7 & 0.4 & 9.2 & 5.5 & 2.6 & 0.9 & 0.3 & 0.1 \\
\hline & enl(x) & 20.4 & 20.0 & 19.2 & 17.3 & 14.5 & 11.5 & 28.5 & 27.6 & 26.1 & 23.5 & 19.9 & 16.2 \\
\hline & ewf(x) & 12.3 & 8.6 & 6.0 & 4.8 & 7.5 & 5.6 & 11.5 & 7.8 & 5.4 & 4.3 & 4.9 & 6.0 \\
\hline & $\operatorname{enf}(x)$ & 19.3 & 18.5 & 16.9 & 14.0 & 7.7 & 6.3 & 26.2 & 25.3 & 23.3 & 20.1 & 15.4 & 10.3 \\
\hline \multirow[t]{6}{*}{ HM } & $\mathrm{e}(\mathrm{x})$ & 32.8 & 28.4 & 24.0 & 19.9 & 16.0 & 12.4 & 38.7 & 34.1 & 29.7 & 25.4 & 21.4 & 17.5 \\
\hline & $\mathrm{p}(\mathrm{x})$ & 0.910 & 0.826 & 0.659 & 0.368 & 0.141 & 0.074 & 0.803 & 0.705 & 0.478 & 0.209 & 0.065 & 0.022 \\
\hline & ewl(x) & 12.1 & 7.9 & 4.3 & 1.9 & 0.8 & 0.4 & 9.2 & 5.5 & 2.6 & 0.9 & 0.3 & 0.1 \\
\hline & enl(x) & 20.7 & 20.4 & 19.7 & 18.0 & 15.2 & 12.0 & 29.5 & 28.6 & 27.1 & 24.6 & 21.0 & 17.3 \\
\hline & ewf(x) & 13.3 & 9.6 & 6.6 & 5.1 & 6.0 & 5.7 & 11.5 & 7.8 & 5.4 & 4.3 & 4.9 & 6.0 \\
\hline & $\operatorname{enf}(x)$ & 19.6 & 18.8 & 17.4 & 14.8 & 10.0 & 6.7 & 27.2 & 26.3 & 24.3 & 21.2 & 16.4 & 11.4 \\
\hline \multirow[t]{6}{*}{ LM } & $\mathrm{e}(\mathrm{x})$ & 30.9 & 26.4 & 22.2 & 18.2 & 14.6 & 11.3 & 36.3 & 31.7 & 27.3 & 23.0 & 18.9 & 15.0 \\
\hline & $\mathrm{p}(\mathrm{x})$ & 0.910 & 0.826 & 0.659 & 0.368 & 0.141 & 0.074 & 0.803 & 0.705 & 0.478 & 0.209 & 0.065 & 0.022 \\
\hline & ewl $(x)$ & 12.0 & $\begin{array}{r}7.020 \\
7.8\end{array}$ & 4.3 & $\begin{array}{l}1.80 \\
1.8\end{array}$ & $\begin{array}{r}0.8 \\
0\end{array}$ & 0.4 & 9.2 & 5.5 & 2.6 & 0.9 & 0.3 & 0.1 \\
\hline & $\mathrm{enl}(\mathrm{x})$ & 19.0 & 18.6 & 17.9 & 16.4 & 13.8 & 10.9 & 27.1 & 26.2 & 24.7 & 22.1 & 18.6 & 14.9 \\
\hline & ewf(x) & 13.2 & 9.4 & 6.5 & 5.0 & 5.8 & 5.5 & 11.5 & 7.8 & 5.4 & 4.3 & 4.8 & 5.8 \\
\hline & $\operatorname{enf}(x)$ & 17.8 & 17.0 & 15.7 & 13.2 & 8.8 & 5.8 & 24.8 & 23.9 & 21.9 & 18.7 & 14.1 & 9.2 \\
\hline \multirow[t]{6}{*}{$\mathrm{HH}$} & $\mathrm{e}(\mathrm{x})$ & 32.8 & 28.4 & 24.0 & 19.9 & 16.0 & 12.4 & 38.7 & 34.1 & 29.7 & 25.4 & 21.4 & 17.5 \\
\hline & $\mathrm{p}(\mathrm{x})$ & 0.910 & 0.834 & 0.713 & 0.425 & 0.191 & 0.074 & 0.803 & 0.736 & 0.569 & 0.329 & 0.141 & 0.022 \\
\hline & ewl(x) & 12.9 & 8.7 & 5.0 & 2.2 & 1.0 & 0.4 & 10.5 & 6.7 & 3.6 & 1.4 & 0.5 & 0.1 \\
\hline & $\operatorname{enl}(\mathrm{x})$ & 20.0 & 19.7 & 19.0 & 17.7 & 15.1 & 12.0 & 28.2 & 27.4 & 26.1 & 24.0 & 20.9 & 17.3 \\
\hline & ewf(x) & 14.1 & 10.4 & 7.1 & 5.3 & 5.1 & 5.8 & 13.1 & 9.2 & 6.4 & 4.5 & 3.3 & 6.1 \\
\hline & $\operatorname{enf}(x)$ & 18.7 & 17.9 & 17.0 & 14.7 & 10.9 & 6.7 & 25.6 & 24.9 & 23.3 & 21.0 & 18.1 & 11.4 \\
\hline \multirow[t]{6}{*}{ LL } & $\mathrm{e}(\mathrm{x})$ & 30.9 & 26.4 & 22.2 & 18.2 & 14.6 & 11.3 & 36.3 & 31.7 & 27.3 & 23.0 & 18.9 & 15.0 \\
\hline & $\mathrm{p}(\mathrm{x})$ & 0.910 & 0.818 & 0.605 & 0.311 & 0.091 & 0.074 & 0.803 & 0.705 & 0.478 & 0.209 & 0.065 & 0.022 \\
\hline & ewl(x) & 11.2 & 7.0 & 3.6 & 1.5 & 0.7 & 0.4 & 9.2 & 5.5 & 2.6 & 0.9 & 0.3 & 0.1 \\
\hline & $\operatorname{enl}(\mathrm{x})$ & 19.7 & 19.4 & 18.6 & 16.7 & 13.9 & 10.9 & 27.1 & 26.2 & 24.7 & 22.1 & 18.6 & 14.9 \\
\hline & ewf(x) & 12.3 & 8.6 & 5.9 & 4.8 & 7.4 & 5.5 & 11.5 & 7.8 & 5.4 & 4.2 & 4.8 & 5.9 \\
\hline & $\operatorname{enf}(x)$ & 18.6 & 17.9 & 16.3 & 13.4 & 7.2 & 5.8 & 24.8 & 23.9 & 21.8 & 18.7 & 14.1 & 9.1 \\
\hline
\end{tabular}

Note: Life expectancy and participation rate projection assumptions are coded $\mathrm{M}$ for medium, $\mathrm{H}$ for high, $\mathrm{L}$ for low, with life expectancy given first, participation rate second. For example, $\mathrm{MH}$ stands for medium life expectancy, high participation rate.

CSP 2010, 37.1-2: 175-206 
both males and females it is approximately three years for those aged 50 in 1976 and in 1991, the years for which observed mortality rates are most complete. A novel finding in the present analysis relates to retirement expectancies, and the difference between the cohort and period estimates. We find that at age 50 the difference ranges from almost 4 years for males aged 50 in 1976 to as little as 1 year for males aged 50 in 2006. Such results have implications for public policy, especially in relation to pensions: the cohort calculations tell us that continued reductions in mortality, and consequent gains in life expectancy, will result in people living longer than is suggested by the period life tables, and that almost all of that gain will be spent in retirement.

The construction of a working life table for a cohort for which some members are still living requires inputs of future mortality and participation rates. Much of the after age 50 history was known to us for cohorts who were aged 50 in 1976, but no information was available for the cohorts aged 50 in 2006. Therefore, for the latter cohorts the results necessarily depend entirely on projections. What we have done is to provide results based on what we term "medium" projections but also redo the calculations using various combinations of "high" and "low" assumptions. In general we find the results to be fairly robust to the choice of assumptions. Period tables - tables based on age-specific rates for a given year - have the advantage that the rates are all known but the disadvantage is that future rates are unknown. Cohort tables allow for changes in age-specific rates across time periods for different cohorts but at the cost of having to forecast future rates, thus introducing some forecasting uncertainty. There is thus a trade off. We think that the trade off favours the cohort tables.

\section{Acknowledgements}

We thank Human Resources and Skills Development Canada for its financial support of the project on which this paper is based, and the Social Sciences and Humanities Research Council for its support of the Social and Economic Dimensions of an Aging Population (SEDAP) Research Program, through its Major Collaborative Research Initiative. We thank also, Rajulton Fernando and an anonymous reviewer appointed by HRSDC for their comments on an earlier draft. Responsibility for any errors rests with the authors.

CSP 2010, 37.1-2: 175-206 


\section{End Notes}

1. When is a "permanent" withdrawal from the labour force really permanent? See Denton and Spencer, (2009), for a survey and discussion of alternative definitions of retirement.

2. One implication of the assumption is that the participation rate for older workers must be a non-increasing function of age. Note that this does not imply a unimodal pattern of participation over the full working age span; a bimodal pattern is quite possible, especially for females, as long as the second mode does not occur after the age of 50. That the non-increasing implication is realistic is supported by an examination of cohort age series back to 1982 for income tax filers reporting earned income, based on other work that we have done using the Statistics Canada Longitudinal Administrative Data file (Denton, Finnie and Spencer 2009).

3. Conventional life table definitions draw a formal distinction between "death rate" and "probability of death". However, for convenience we use the terms interchangeably in this paper.

\section{References}

Babel, Bernhard, Eckart Bomsdorf, and Rafael Schmidt. 2007. "Future life expectancy in Australia, Europe, Japan and North America." Journal of Population Research 24(1): 119-131.

Bélanger, Alain and Daniel Larrivée. 1992. "New approach for constructing Canadian working life tables, 1986-1987." Statistical Journal of the United Nations Economic Commission for Europe 9: 27-49.

Booth, Heather and Leonie Tickle. 2004. "Beyond three score years and ten: Prospects for longevity in Australia." People and Place 12(1): 15-27.

Chow, Rita, Parameswara Krishnan, and N. Lalu. 1986. "Female working life expectancy, Canada 1921-1971: Results from an application of model working life tables." Canadian Studies in Population 13(2): 181-192.

CSP 2010, 37.1-2: 175-206 
Denton, Frank T., Christine H. Feaver, and Byron G. Spencer. 1994.

"Economic-demographic projection and simulation: A description of the MEDS system of models." Studies in Applied Demography: Proceedings of the International Conference on Applied Demography. Bowling Green University, Bowling Green, Ohio.

Denton, Frank T., Christine H. Feaver, and Byron G. Spencer. 2005a. "MEDS-D User's Manual." Research Report No. 400, Research Institute for Quantitative Studies in Economics and Population. McMaster University, Hamilton, Ontario.

Denton, Frank T., Christine H. Feaver, and Byron G. Spencer. 2005b. “Time series analysis and stochastic forecasting of mortality and life expectancy." Journal of Population Economics 18: 203-227.

Denton, Frank T., Ross Finnie, and Byron G. Spencer. 2009. "Income replacement in retirement: Longitudinal evidence from income tax records." Research Report No 436, Research Institute for Quantitative Studies in Economics and Population, McMaster University, Hamilton, Ontario.

Denton, Frank T. and Sylvia Ostry. 1969. Working Life Tables for Canadian Males. Dominion Bureau of Statistics (now Statistics Canada), Ottawa.

Denton, Frank T. and Byron G. Spencer. 2009. "What is retirement? A review and assessment of alternative concepts and measures." Canadian Journal on Aging 28(1): 63-76.

Gnanasekaran, K.S. and G. Montigny. 1975. Working Life Tables for Males in Canada and Provinces, 1971. Statistics Canada, Ottawa.

Hall, Peter. 1985. "Resampling a coverage pattern." Stochastic Process Applications 20(2): 231-246.

Härdle, Wolfgang. 1990. Applied Nonparametric Regression. Cambridge Cambridge University Press.

Jones, Stephen R.G. and W. Craig Riddell. 1998. "Gross flows of labour in Canada and the United States." Canadian Public Policy XXIV: 103-120.

Keyfitz, Nathan. 1968. Introduction to the Mathematics of Population. Reading, Massachusetts: Addison-Wesley. 
Keyfitz, Nathan and H. Caswell. 2005. Applied Mathematical Demography. Third Edition. New York: Springer.

Künsch, Hans R. 1989. “The jackknife and the bootstrap for general stationary observations." Annals of Statistics 17(3): 1217-1261.

Lee, Chulhee. 2001. "The expected length of male retirement in the United States, 1850-1990.” Journal of Population Economics 14: 641-650.

Lee, Ronald and Lawrence Carter. 1992. "Modeling and forecasting U.S. mortality." Journal of the American Statistical Association 87: 659-671.

Lee, Ronald and Shripad Tuljapurkar. 1994. "Stochastic population forecasts for the United States: Beyond high, medium and low." Journal of the American Statistical Association 89: 1175-1189.

McCollister, George and Christopher Pflaum. 2007. "A note on the steady state assumption and expectancy bias." Journal of Legal Economics 14(2): 85-96.

Nurminen, Markku, Christopher Heathcote, and Brett Davis. 2005. "Working life expectancies of aging Finnish workers in the Municipal Sector." The Internet Journal of Epidemiology 2(1).

Shryock, Henry S. and Jacob S. Siegel. 1971. The Methods and Materials of Demography, Volumes 1 and 2. U.S. Bureau of the Census. Government Printing Office, Washington, D.C.

Skoog, Gary R. and James E. Ciecka. 2006. "Worklife expectancy and competing risks: Multiple decrement theory with an application to railroad workers." Journal of Forensic Economics 19: 243-260.

Smith, Shirley J. 1982. Tables of Working Life: The Increment-Decrement Model. Bureau of Labor Statistics Bulletin 2135. U.S. Department of Labor, Washington, D.C.

Smith, Shirley J. 1986. Worklife Estimates: Effects of Race and Education. Bureau of Labor Statistics Bulletin 2254. U.S. Department of Labor, Washington, D.C.

Statistics New Zealand (2006). A History of Survival in New Zealand: Cohort Life Tables 1876-2004. Aukland, New Zealand. 
Whistler, Diana, Kenneth White, S. Donna Wong, and David Bates (2004).

SHAZAM Econometrics Software, Version 10: User's Reference Manual. Northwest Econometrics, Ltd., Vancouver, British Columbia.

Wilmoth, John. 2005. "On the relationship between period and cohort mortality.” Demographic Research 13(11): 231-280.

Wolfson, Michael and Geoff Rowe. 2001. "Perspectives on Working Time over the Life Cycle," in Working Time in Comparative Perspective, Volume II - Life-Cycle Working Time and Nonstandard Work. S. Houseman and A. Nakamura (eds.), Kalamazoo, MI: WE Upjohn Institute for Employment Research. 